وعي الريفيات بخاطر بصض الممارسات اليومية السلبية على صحة الإنسان بإحي قري مركز كفر الدوار

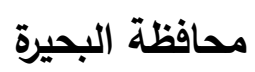

\author{
سميرة احمد قنديل ', ايناس خميس', هيام حسيب'و سامية عباس مصطفى'

\section{المقدمة والمشكلة البحثية}

\section{الملخص العربى}

ان القضايا البيئية تعد من القضايا الملحة محليا ودوليا

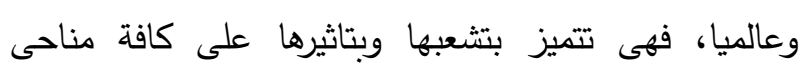

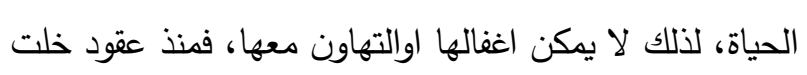

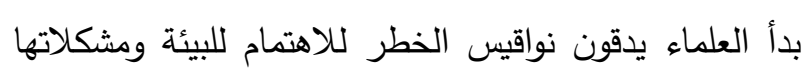

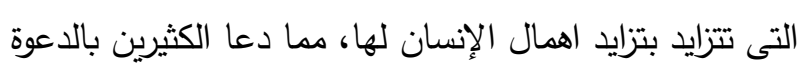

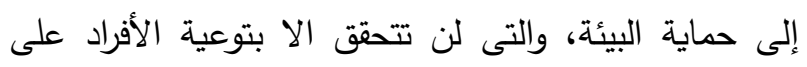

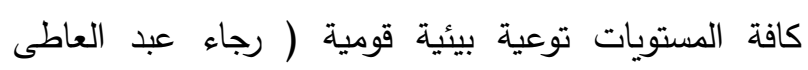
. (r.) V ، وتؤكد العديد من الدراسات العلمية، إن جمهورية مصر

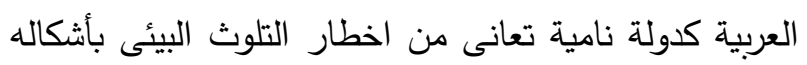

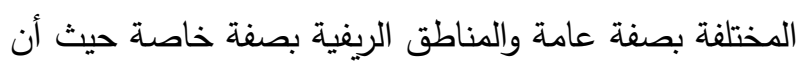

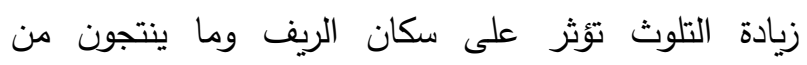

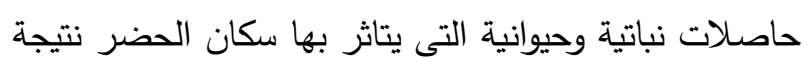

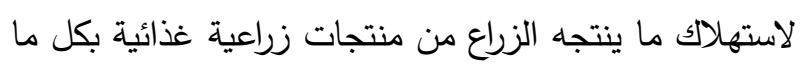

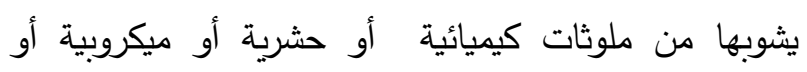
فطرية ( صبرى صالح، ع. ؟ ب ).

كما أن هناك عدة مخاطر تلحق بالبيئة الريفية نتيجة

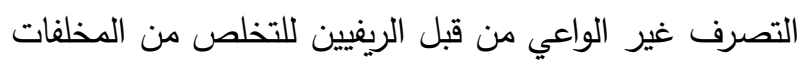

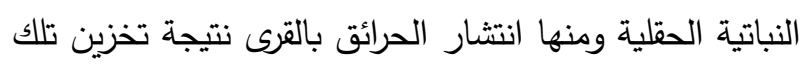
المخلفات فوق أسطح المنازل المجاورة، وإصابة الأفراد بالعديد

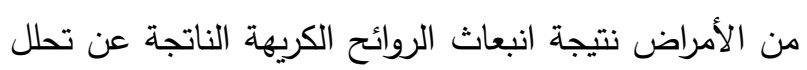

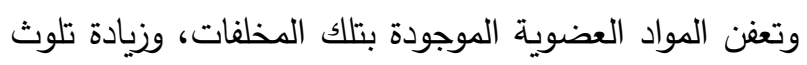
الهواء نتيجة حرق هذه المخلفات، بالإضافة إلى تكاثر
استهذف هذا البحث بصفة أساسية التعرف على مستوي

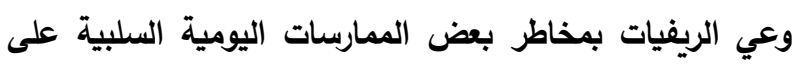

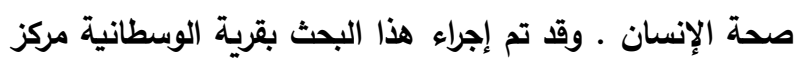

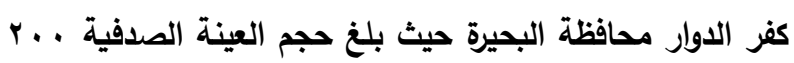

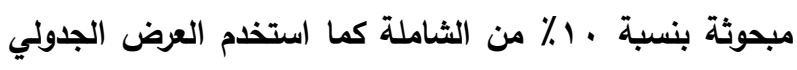

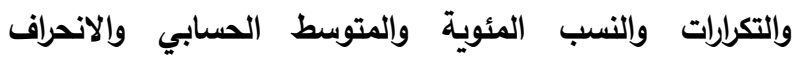

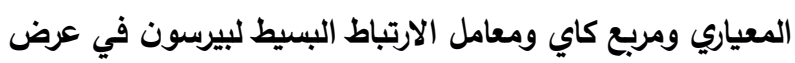
وتحليل النتائج.

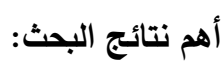

1-أكثر من ربع العينة ما بين أمية وتقرأ وتكتب بنسبة هـ ـ ؟ب٪. r- أن نصف المبحوثات تتمتعن بآداء جيد للممارسات السلبية

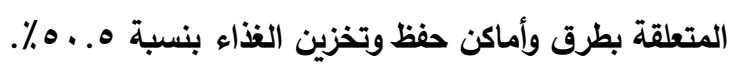

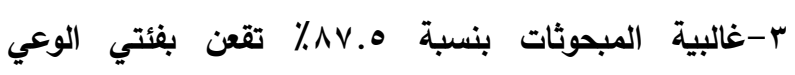

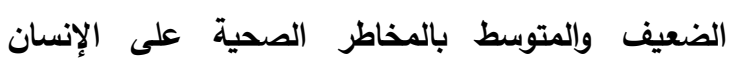

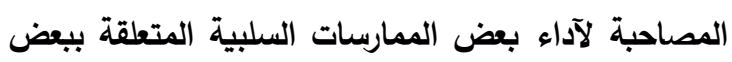
المعاملات داخل المنزل

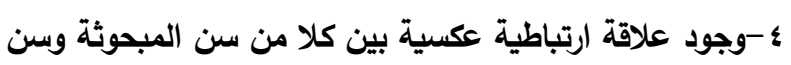

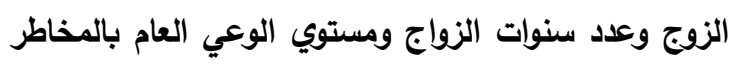

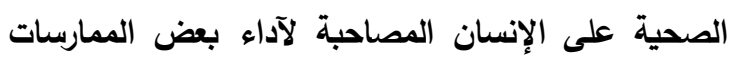
السلبية المتعلقة ببعض المعاملات داخل المنزل. الكلمات الدلالية: عي الريفياتـ الممارسات السلبية للريفيات. المخاطر الصحية

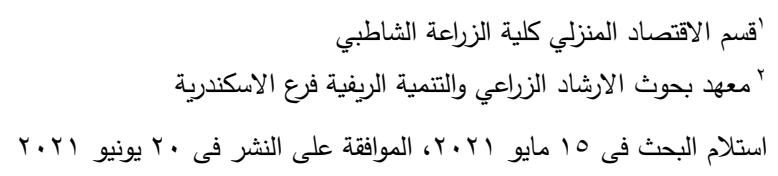




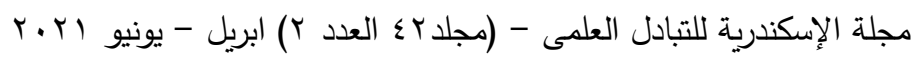

هذه الأمراض التيفوئيد والكوليرا والتهاب الكبد الفيروسي وغيرها، r- الأمراض المرتبطة بتلوث الهواء وهذه تؤدي هي الأخرى إلى الإصابة بالكثير من الأمراض ومنها امراض لاض لهراض التتفس والصدر كالربووالحساسية والتهاب القصبات الهوائية، r- الأمراض النفسية الناجمة عن الضوضاء والضجيج بسبب المعامل والمطارات القريبة من المناطق السكنية وهذه تؤدي إلى شعور الفرد بعدم الراحة والإصابة بأمراض نفسية حادة نتيجة التوتر العصبي والارق وعدم النوم والثعور بالضيق وفقدان التركيز والاستيعاب ومشاكل نفسية اخرى كثيرة تؤدي إلى مشاكل اجتماعية خطيرة ربما تؤدي إلى حصول تصادم بين أفراد المجتمع فضلا عن تكلفة معالجة هذه الأمراض، ونتيجة كل ذلك هو تراجع إنتاجية هؤلاء الأفراد في جميع المجالات (حسين الثمري 10 • ب). كما

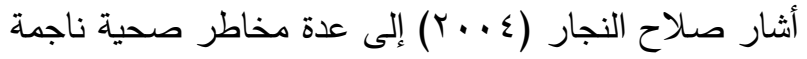
عن التلوث البيئي على النحوالتالي: ا-اصابة الإنسان بالعديد من الأمراض مما يجعله عاجزا عن العمل فيقل الإنتاج، ب-اهدار الموارد البشرية مما يؤثر على الأمن القومي والاجتماعي، ب- تحمل الدولة التكاليف العلاجية والدوائية المصابين بالأمراض، ع- انتشار الأمراض المعدية، 0-تهديد صحة وحياة الأطفال، $1-$ ارتفاع نسبة الوفيات،

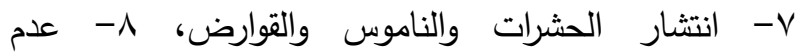
الاستمتاع بالطبيعة الجميلة، و- إيذاء العين والأنف بأثكال وروائح غير مرغوب فيها (جابر شحاته وسوزان الثربتلي، . ( r.. إن صحة الإنسان تعكس سلامة النظام الايكولوجي الذي يعيش فيه لذا فلابد من توافر الحد الادنى من الهواء النظيف، والمياه النقية، والبيئة النظيفة الخالية من المخلفات المنزلية والزراعية التي تئثر سلبا على صحته، فقد شهد القرن العشرين ظهور امراض مزمنة، وامراض وبائية معدية بالاضافة إلى بعض الفيروسات تسبب للانسان والحيوان امراضا مختلفة (صلاح النجار ع . . ب).
القوارض والزواحف والحشرات، وإهدار هذه المخلفات كمورد اقتصادي هام، كما يؤدي تراكم هذه المخلفات في الحقول إلى استقطاع مساحات من الأراضي الزراعية وتاخير عمليات الخدمة الزراعية لمحاصيل الموسم التالي، كذلك يؤدي حرق بقايا المحاصيل في الأراضي الزراعية إلى الإضرار بخصوبتها وإنتاجيتها وموت الكائنات الحية المفيدة للتربة الزراعية والتي تزيد من خصوبتها، ومما سبق يتضح أن البيئة الريفية تواجه عدة مخاطر بيئية وصحية ناجمة عن السلوك غير الواعي من قبل الرينين نتيجة سوء استخدام المبيدات الحشرية والأسمدة الكيماوية والتخلص من المخالفات والفضلات الآدمية وحرق المخلفات المحاصيل

$$
\text { الزراعية (جمال عيسوي، (...广). }
$$

وتؤدي الممارسات الخاطئة والاستخدام غير الرشيد لها إلى تغيير في تركيب وخواص الأراضي الزراعية، واختلال التوازن البيئي وتلوث عناصر البيئة المختلفة من تربة وماء وهواء ونبات وحيوان، وهكذا تواجه البيئة الزراعية بالريف المصري أخطارا داهمة تؤدي إلى تلوثها نتيجة لما تتعرض له له من الممارسات الخاطئة لسكانها والتي تعد مصدرا للتلوث مما يؤثر على الزراع وحيواناتهم ونباتهم حيث يؤثر تلوث البيئة

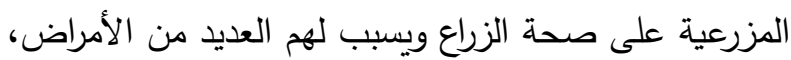
كما يؤثر على قدراتهم الإنتاجية، كما يؤثر على الحيوانات المزرعية ويصيبها بالعديد من الأمراض ما يقلل من إنتاجها، وذلك لما يقوم به الزراع من ممارسات خاطئة مثل الاسراف في استخدام المبيدات والأسمدة الكيماوية وسوء التخلص من لن بـ

$$
\text { المخلفات المزرعية والمنزلية (حنان ذكي، ـ ( • ب). }
$$

إن تفاقم التلوث البيئي بجميع أثكاله (سواء في الهواء

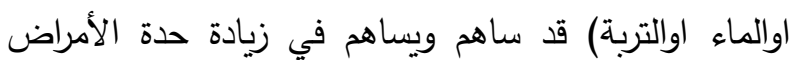
التي تؤثر سلبا على الحالة والنفسية لأفراد المجتمع وظهور

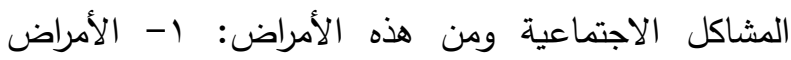
المرتبطة بتلوث المياة تشكل الأمراض التي تتتقل عدواها بواسطة المياه مشكلة خطيرة من مشاكل الصحة العامة ومن 
بعض الدراسات من انخفاض وعيها البيئ وما ينجم عنه من

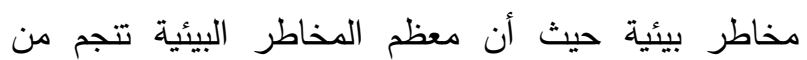
الأنماط السلوكية الخاطئة للمراة الريفية كما تمثل العمود لمجتمعها الريفى فهى تقوم بأدوار متعددة فى مجال التتمية الزراعية وذلك من خلال مساهماتها فى غالبية الأنشطة الزراعية التى تتم فى الحقل فهى تتحمل العبء الاكبر هن والمسئولية عن زراعة بعض المحاصيل وادارة العمليات

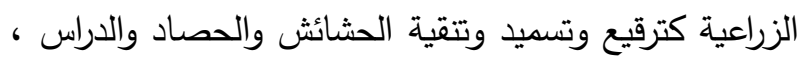
والتخزين، كما تساهم أيضا فى الأنشطة التى تتم داخل ولت ولت ولته

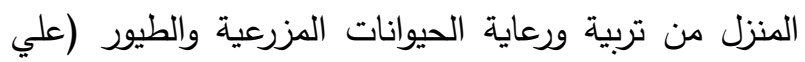

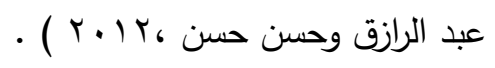
ومما سبق تتضح مشكلة الدراسة الحالية والتي تتبلور في أهمية دراسة الأنماط السلوكية للريفيات ازاء البيئة ، نظرا لان معظم المشاكل البيئية وانتشارا الأمراض التي تتجم عن سوء تلك الأنماط السلوكية فى التعامل مع البيئة والتى تعزى بدورها إلى انخفاض الوعى البيئى والصحى ولذلك لابد من

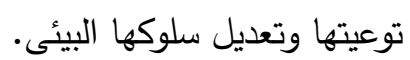

من هنا تبرز الحاجة الي عملية تعليمية ارشادية

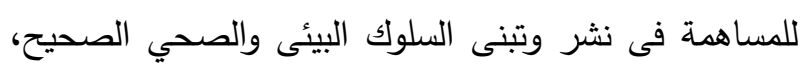
وتحديد الإجراءات التى يجب أن تتبعها المراة الريفية للوقاية من المخاطر البيئية التى تحيط بها والتى تؤثر على الصحة والاسرة، وفقا لما سبق فقد استلهمت الباحثة اهمية إجراء هذا البحث لما قد يسفر عنه من نتائج تعد بمثابة ركائز في تتمية

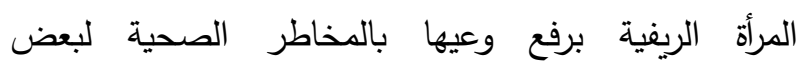
الممارسات اليومية السلبية وذلك من خلال عمل برامج براه ارشادية موجهة بمنطقة البحث.

\section{الأهداف البحثية}

استهدف هذا البحث بصفة أساسية قياس وعي الريفيات

بمخاطر بعض الممارسات اليومية السلبية على صحة الإنسان بإحدى قرى مركز كفر الدوار محافظة البحيرة.
ويمكن تلخيص المخاطر البيئية الريفية إلى عدة مخاطر ومنها المخاطر الصحية الريفية حيث انتشار الأمراض مثل إلى الأمراض المعدية وهى ميكروبات ممرضة من جراثيم وفيروسات وطفيليات اوفطريات تتتشر بشكل مباشر اوغير مباشر من شخص مصاب إلى شخص سليم، والفشل الكلوى ، والالتهاب الكبدى، ومخاطر المسكن الريفى والتى تتمثل فى مي سلى الازدحام وتربية الطيور المنزلية وما ينتج عن امراض انفلونزا الطيور كذلك انتشار الحشرات المنزلية المتتوعة من الذباب والصراصير والنمل وحشرات الفراش وغيرها والتى تعيش داخل المنزل الريفى وتسبب نقل الأمراض الخطيرة ،كما أن المخاطر البيئية الزراعية تتمثل فى التسميد غير المتوازن واغفال التسميد العضوى ، كذلك الاستخدام العشوائى للهرمونات ومنظمات النمو, ومن المخاطر ايضا تدهور خصائص التربة الزراعية من تجريف التربة وشيوع الملوحة والقلوية والتصحر وهوتحول مساحات واسعة عالية الإنتاج إلى مساحات فقيرة بالحياة النباتية والحيوانية ،والاسراف فى الرى والرى بمياه الصرف ، وافساد الصرف المغطى وانتشار

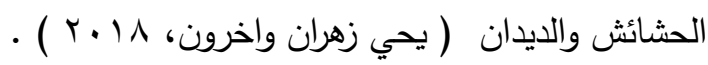
ولذلك يعد الوعى بالمخاطر الصحية الناجمة عن التلوث البيئى ذو اهمية متزايدة ليس فيما يتعلق بالجوانب الجسدية فحسب وانما بالجوانب النفسية ايضا ،وقد قاد الفهم المتزايد للعلاقة الكامنة بين السلوك والصحة الي حدوث تحولات كبيرة فى العقود الثلاثة الااخيرة من القرن العشرين فى فهم الصحة وتتميتها ، وامكانية التاثير فيها على المستوى الفردى ، فلم تعد الصحة مفهوما سلبيا يمكن تحقيقها فى كل الاحوال بل اصبحت مفهوما ديناميكيا يحتاج إلى جهد وبذل من قبل الأفراد فى سبيل تحقيقها والحفاظ عليها ( سامر راضوان، . $(r \cdot 10$

وحيث أن المراة الريفية من أكثر فئات المجتمع تاثيرا وتاثرا بالتدهور البيئى وذلك لادوارها المتعددة وما يرتبط بها من ممارسات ذات الارتباط المباشر ، ولما اظهرته نتائج 


$$
\text { مجلة الإسكندرية للتبادل العلمى - (مجلد \& العدد r) ابريل - يونيو ابr r }
$$

بمخاطر بعض الممارسات اليومية السلبية على صحة الإنسان.

الفرض الثاني : لايوجد ارتباط معنوي بين كل من سن المبحوثة، سن الزوج، عدد سنوات الزواج كمتغيرات مستقلة و الوعي بمخاطر بعض الممارسات اليومية السلبية على صحة • الإنسان

$$
\text { الأسلوب البحثي }
$$

\section{أولا: التعربفات الإجرائية وقياسها:}

الممارسات اليومية السلبية: يقصد بها في هذا البحث

بعض الممارسات السلبية ذات الصلة بكل من المحاور

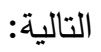

( ) طرق وأماكن حفظ وتخزين المواد الغذائية.

$$
\text { r) بعض المعاملات داخل البيئة المنزلية. }
$$

r) التخلص من المخلفات المنزلية والحيوانات النافقة. وتم قياسه بتوجيه مجموعة اسئلة للمبحوثة في ثلاثة محاور يتكون كل محور من ثلاثة عشر سؤالا بحيث تاخذ المبحوثة ثلاثة درجات في حالة الاجابة بدائما والدالة على لئ ادائها للممارسة السلبية بثكل منتظم ودرجتان في حالة الاجابة باحيانا والدالة على ادائها للممارسة السلبية بشكل

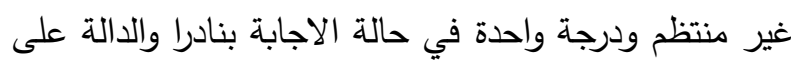
عدم ادائها لهذه الممارسة السلبية وعليه تراوح المدى النظري

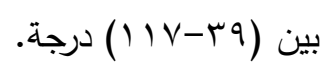

\section{وعي الريفيات بمخاطر بعض الممارسات اليومية}

السلبية: وهو إلمام المرأة الريفية بالمخاطر الصحية الناجمة عن بعض ممارساتها اليومية السلبية، وتم قياسة بتوجيه مجموعة اسئلة للمبحوثة في ثلاثة محاور يتكون كل محور من ثلاثة عشر سؤالا بحيث تاخذ المبحوثة ثلاثة درجات في حالة الاجابة بنعم والدالة على معرفتها بالاضرار الصحية لممارستها علي الإنسان ودرجتان في حالة عدم معرفتها بالاضرار من عدمها ودرجة واحدة في حالة الاجابة بلا والدالة على معرفتها الخاطئة بالاضرار الصحية لممارستها ولها لهاه
وينبثق من هذا الهدف الرئيسي مجموعة من الأهداف

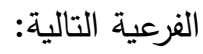

1-التعرف على بعض الخصائص الأسرية والثخصية للمبحوثات

r-تحديد المستوى العام لبعض الممارسات اليومية السلبية للمبحوثات بمنطقة البحث

r-تحديد المستوى العام لوعي المبحوثات بمخاطر بعض الممارسات اليومية السلبية على الإنسان بمنطقة البحث

ع-دراسة العلاقات الارتباطية بين كل من مستوى وعي المبحوثات العام بمخاطر بعض الممارسات اليومية السلبية على الإنسان من جهة وكل من المتغيرات المستقلة المدروسة من جهة اخرى الإسئ هن

\section{الأهمية التطبيقية للبحث}

من منطلق أن المرأة نصف المجتمع وهي المسئول الاول عن رعاية الاسرة فواجب الحفاظ على صحتها امر أساسي لتمكن من الحفاظ على صحة بقية الاسرة ومن هنا يسعي البحث للتعرف علي مستوى آداء بعض الممارسات اليومية السلبية التي تقوم بها المرأة الريفية وذات صلة بصحة الإنسان ليس هذا فحسب وانما ايضا التعرف على مدي المامها بمخاطر هذه الممارسات على صحة الإنسان فالنتائج التي قد يسفر عنها البحث قد تساعد متخذي القرار في وضع برامج ارشادية تتموية للمرأة الريغية بمنطقة البحث في مجال الوعي بمخاطر بعض الممارسات اليومية السلبية علي صحة

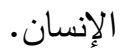

\section{الفروض البحثية}

تم صياغة الفروض البحثية في صورتها الصفرية كما يلي: الفرض الأول: لايوجد اقتران معنوي بين كل من الحالة

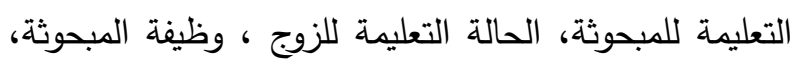
مشاركة الزوج في الزراعة، التعرض لمصادر المعلومات، الاستفادة من مصادر المعلومات كمتغيرات مستقلة و الوعي 
مشاركة الزوج في الزراعة، التعرض لمصادر المعلومات،

الاستفادة من مصادر المعلومات.

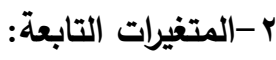

المستوى العام لبعض الممارسات اليومية السلبية لمبحوثات.

المستوى العام لوعي المبحوثات بخاطر بعض

الممارسات اليومية السلبية على الإنسان.

خامسا: أسلوب جمع وتحليل البيانات :

تم جمع البيانات باستخدام استمارة إستبيان بالمقابلة

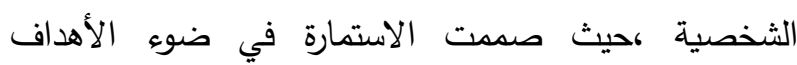
البحثية كأداة من أدوات البحث العلمي على عدة محاور وهي: ا - طرق وأماكن حفظ وتخزين المواد الغذائية. r- بعض المعاملات داخل البيئة المنزلية. r- التخلص من المخلفات المنزلية والحيوانات النافقة. اختبار صدق وثبات الاستبيان:

تم حساب صدق المقاييس المستخدمة في الاستبيان باستخدام معامل الفاكرونباخ كما هو موضح بجدول رقم (Y)، وتم حساب ثبات مقاييس الاستبيان عن طريق معامل الأرتباط بين نتائج تطبيق الاستبيان على عينة من المبحوثات

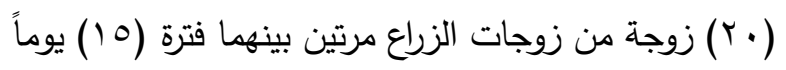

السلبية على الإنسان وعليه تراوح المدى النظري بين (وب-

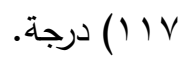
ثانيا: منهج البحث:

اتبع في هذا البحث المنهج الوصفي التحليلي, الذي يعمل على تحديد الظروف والعلاقات التي توجد بين الوقائع وجمع البيانات وتبويبها.

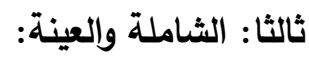
تعد محافظة البحيرة من أكبر المحافظات الزراعية بجمهورية مصر العربية وتتكون من 10 مركزاً إدارياً ،ويشمل معل كل مركز عدد من القرى وتحتوي على العديد من أنواع الأراضي المختلفة حيث بها اراضي قديمة طينية واراضي مني جديدة رملية وتجود بها معظم الزراعات التي يحتاجها

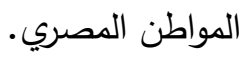
وتم اختيار مركز كفر الدوار باعتباره من أقدم المراكز الزراعية بالمحافظة وتم اختيار قرية الوسطانية وبلغت شاملة الدراسة سب. r من زوجات الزراع الحائزين بالقرية، و تم أختيار عينة صدفية بنسبة . 1\% من الثاملة لتبلغ عينة البحث .. زوجة (ادارة المعلومات والاحصاء بمديرية

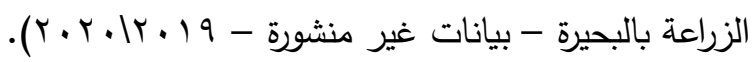
رابعا: المتغيرات البحثية : 1-المتغيرات المستقلة : سن المبحوثة، سن الزوج، عدد سنوات الزواج ,الحالة التعليمة للمبحوثة، الحالة التعليمة للزوج ، وظيفة المبحوثة، لرنا،

جدول ا.قيم معامل الفا كرونباخ لمحاور الاستبيان الخاصة بسلوك المبحوثات العام ووعيهن بمخاطره على صحة الإنسان

\begin{tabular}{|c|c|c|c|c|}
\hline عداد العبارات & رقم المخبارات & كرونباخِ بعد الفا & كرونباخِ قبل الفال & المحور \\
\hline 14 & $1 \varepsilon$ & $\because \vee \wedge$. &..$\vee \curlyvee \wedge *$ & طرق وأماكن حفظ وتخزين المواد الغذائية \\
\hline r & 1. &.$\vee V \cdot$ &..$\vee 00 *$ & بعض المعاملات داخل آلبيئة المنزلية \\
\hline 14 & r & $.7 \mathrm{TV}$ &. $.09 \mu^{*} *$ & التخلص من المخلفات المنزلية والحيوانات النافقة \\
\hline
\end{tabular}


أن بـء من الازواج يقعوا في الفئة العمرية هب إلى اقل من

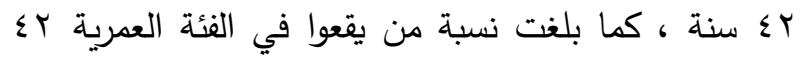

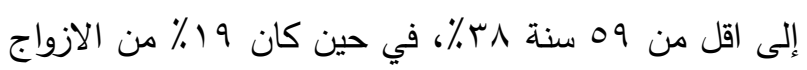

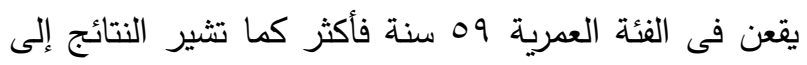

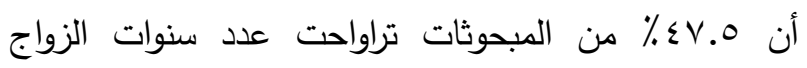
لديهن من 1 إلى اقل من 10 سنة، وان اكثر من ثلث العينة

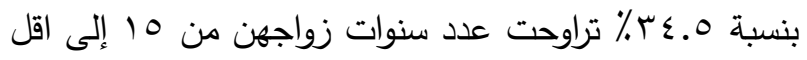

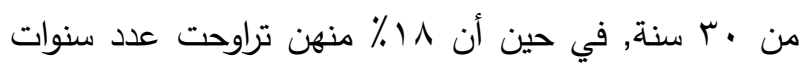

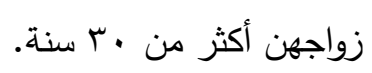

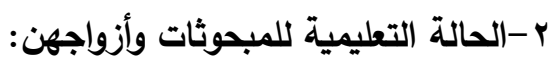
تشير نتائج جدول (ץ) إلى أن اكثر من ثلث المبحوثات

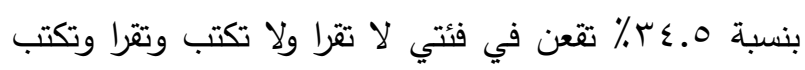

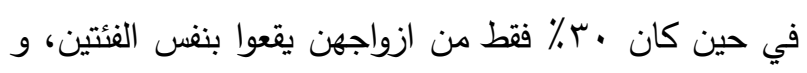

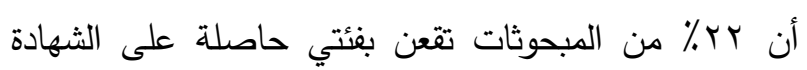

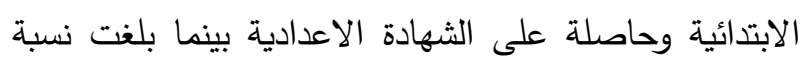

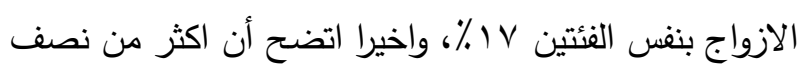

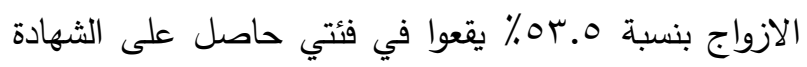

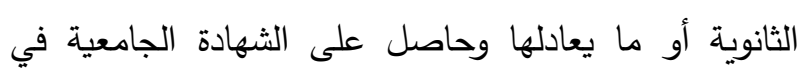
مقابلة ه.rی ٪ من المبحوثات تقعن بنفس الفئتين.
من خارج عينة الدراسة بغرض التعرف على دقة ووضوح

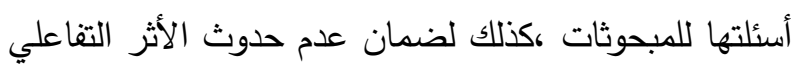

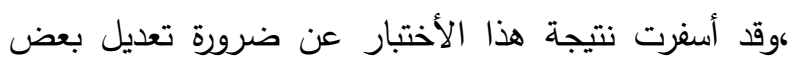

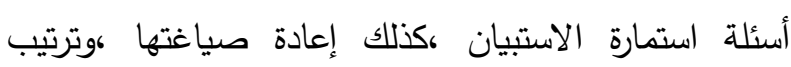
وتغيير بعضها ،ومن ثم فقد أجريت التعديلات اللازمة على العى مانى الاستمارة ،وتم صياغتها في صورتها النهائية .

\section{النتائج البحثية ومناقشتها}

أولا: بعض الخصائص الأسرية والثخصية للمبحوثات:

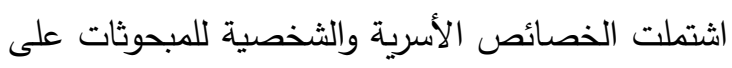

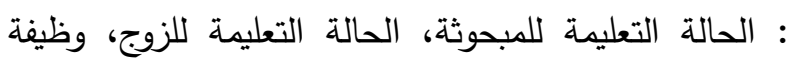

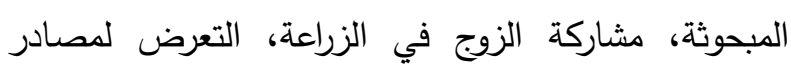

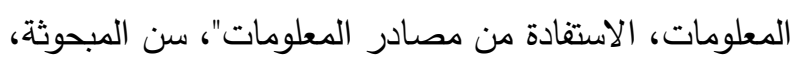

$$
\text { سن الزوج،عدد سنوات الزواج. }
$$

ا-سن المبحوثات وأزواجهن وعدد سنوات الزواج:

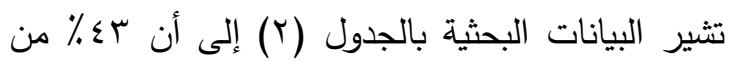

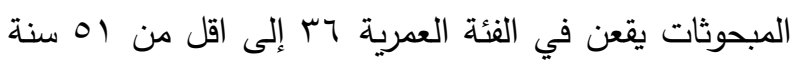

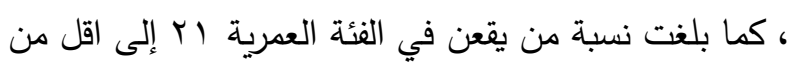

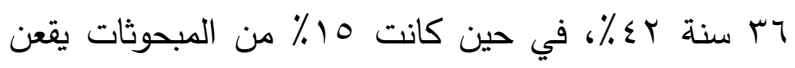

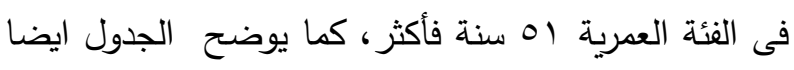

جدول r. توزيع المبحوثات وأزواجهن وفقا للسن وعدد سنوات الزواج

\begin{tabular}{|c|c|c|c|c|c|c|c|c|c|c|}
\hline$\%$ & العدد & الزواج & علد سنوات & $\%$ & 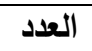 & & سن الزوج & $\%$ & العدد & سن المبحوثات \\
\hline$\varepsilon \vee .0$ & 90 & & $10>1$ & $\varepsilon r$ & $\Lambda T$ & & $\varepsilon r>r_{0}$ & $\sum r$ & $\Lambda \varepsilon$ & $r r>r \mid$ \\
\hline$r \leqslant .0$ & 79 & & $r .>10$ & rᄉ & $V_{4}$ & & $0 q>\leqslant r$ & « & 人т & $01>r 4$ \\
\hline in.. & די & & r. فأكثر. & 19 & ra & & 9 ه فأكثر & 10 & $r$. & 10 لم فأكثر \\
\hline \multirow[t]{3}{*}{$1 \ldots$} & r... & & المجموع المجوع & $1 \ldots$ & r... & & المجموع & $1 \ldots$ & r.. & المجموع \\
\hline & 1 & درجة & مشاهذة & & To & درجة & مشاهذة & & Y) & أصغز درجة مشاهدة \\
\hline & « & شاهدة & أكبر درجة & & vo & درجة & مشاهداة & & 70 & أكبر درجة مشاهدة \\
\hline \multicolumn{2}{|c|}{ K.TY \pm V..r } & \pm & الانحراف & IT.VT & $\varepsilon \varepsilon .9$ & \pm & الانحراف & IT.rs & $=r \Lambda .7$ & المعياريط \pm الانحراف \\
\hline
\end{tabular}




\begin{tabular}{|c|c|c|c|c|}
\hline \multicolumn{2}{|c|}{ الزوج } & \multicolumn{2}{|c|}{ المبحوثات } & \multirow[t]{2}{*}{ الحالة التعليمية } \\
\hline$\%$ & العدد & $\%$ & العدد & \\
\hline 10.0 & M & $r \cdot .0$ & $\varepsilon 1$ & لا تقرأ ولا تكتب \\
\hline $1 \leqslant .0$ & $r q$ & $1 \leq$. & r^ & تقرأ وتكتب \\
\hline $1 .$. & r & Y.o & 0 & الثهادة الابتدائية \\
\hline 17. & r & 19.0 & rq & الشهادة الاعدادية \\
\hline$\leqslant \vee .0$ & 90 & rV.o & vo & الشهادة الثانوية \\
\hline 0.0 & 11 & 7.. & Ir & الشهادة الجامعية \\
\hline $1 \ldots$ & $r \ldots$ & $1 \ldots$ & $r \ldots$ & المجموع \\
\hline
\end{tabular}

كما تثير نتائج جدول (؟) إلى أن ^ץ\%٪ من المبحوثات

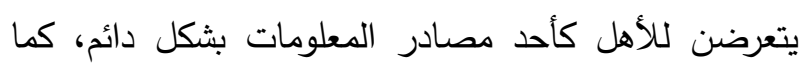

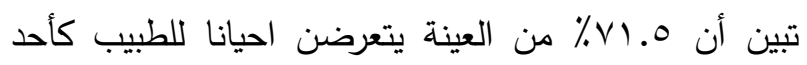

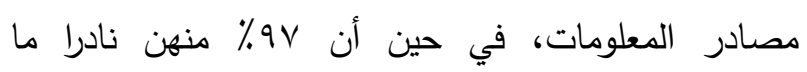
يتعرضن للأجتماعات الارشادية كأحد مصادر المعلومات. ه- الاستفادة من مصادر المعلومات:

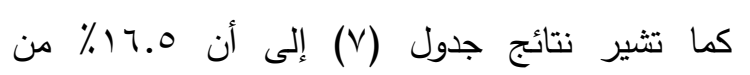

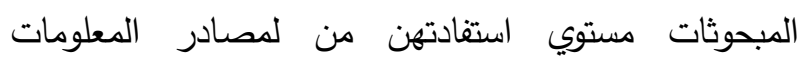

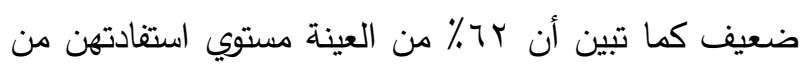

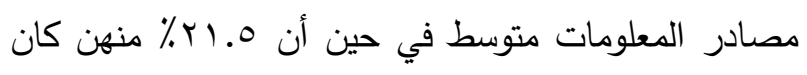
مستوي استفادتهن من مصادر المعلومات جيد.
ץ-الحالة الوظيفية للمبحوثات ومشاركتهن للزوج في

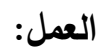

توضح نتائج جدول (£) أن أكثر من نصف العينة من

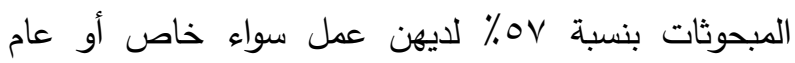

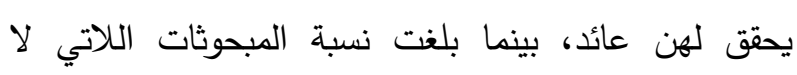

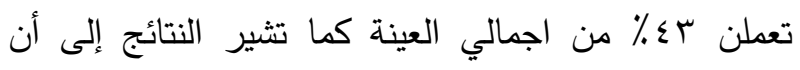

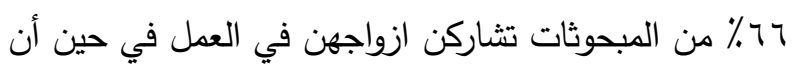

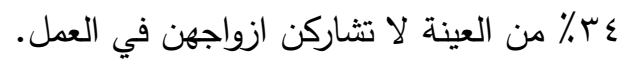
ع -التعرض لمصادر المعلومات:

تثير نتائج جدول (0) إلى أن ه. ب\% من المبحوثات

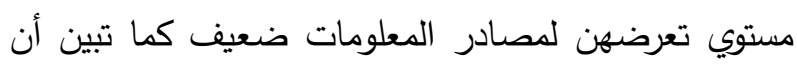

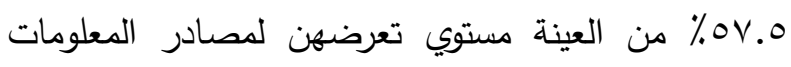
متوسط في حين أن بار \% منهن كان مستوي تعرضهن

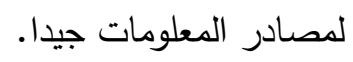

\begin{tabular}{|c|c|c|c|c|c|}
\hline \multicolumn{6}{|c|}{ جدول ـ ـ توزيع المبحوثات وفقا للحالة الوظيفية ومشاركتهن للزوج في العمل } \\
\hline$\%$ & العدد & مشاركة الزوج في العمل & $\%$ & العدد & الحالة الوظيفية \\
\hline$r \varepsilon$ & $7 \curlywedge$ & لا تشارك & $\varepsilon r$ & 17 & لا تعمل \\
\hline 77 & IKr & تشارك & or & $11 \varepsilon$ & تعمل \\
\hline $1 \ldots$ & $r \ldots$ & المجموع & $1 \ldots$ & $r \ldots$ & المجموع \\
\hline
\end{tabular}

\begin{tabular}{|c|c|c|}
\hline$\%$ & العات & الفئات 0 ـ توزيع المبحوثات و \\
\hline r9.0 & 09 & 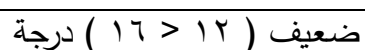 \\
\hline $0 Y .0$ & 110 & متوسط (' 17 > . (Y) درجة \\
\hline$\pi$ & rt & جيد (مب درجة فأكثر) \\
\hline $1 \ldots$ & $r \ldots$ & المجموع - ال الموع \\
\hline
\end{tabular}




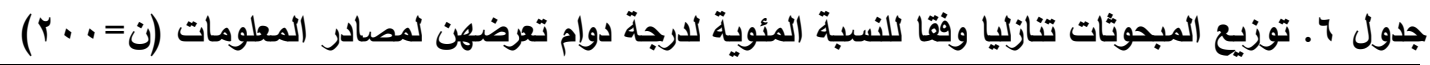

\begin{tabular}{|c|c|c|c|c|c|c|}
\hline \multicolumn{6}{|c|}{ لدرجة التعرض } & \multirow{3}{*}{ مصادر المطلومات } \\
\hline \multicolumn{2}{|c|}{ نادرا } & \multicolumn{2}{|c|}{ احيانا } & \multicolumn{2}{|c|}{ دائما } & \\
\hline$\%$ & عدد & $\%$ & عدد & $\%$ & عدد & \\
\hline r.o & 0 & 09.0 & 119 & ri & V7 & الأهل \\
\hline 9 & 11 & 09.0 & 119 & r..0 & זי & التليفزيون \\
\hline $1 V .0$ & ro & $T \varepsilon$ & irs & 11.0 & rV & الاصدقاء \\
\hline 1. & $r$. & $v 1.0$ & $1 \leqslant r$ & 11.0 & tr & الطبيب - ل كبي \\
\hline iv & $\Gamma \varepsilon$ & 77.0 & זr & 17.0 & Tr & الجيران \\
\hline$\leqslant V .0$ & 90 & or & $1 . \varepsilon$ &. .0 & 1 & الراديو \\
\hline $9 v$ & $19 \varepsilon$ & Y.O & 0 &. .0 & 1 & الاجتماعات الارشادية \\
\hline Tr & ITE & rی & vi & - & · & الرائدة الريفية \\
\hline vo & 10 & ro & 0. & . & . & الجرائد والَّهجلات \\
\hline 99 & 191 & 1 & r & . & . & النشرات الارشادية \\
\hline
\end{tabular}

جدول V.توزيع المبحوثات وفقا لاجمالي درجة الاستفادة من مصادر المعلومات

\begin{tabular}{|c|c|c|}
\hline$\%$ & 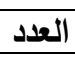 & الفئات \\
\hline 17.0 & $r \mu$ & ضعيف ( ז > 17 ) درجة \\
\hline$\pi$ & ITs & متوسط (' 17 > • ب) درجة \\
\hline r..0 & $\varepsilon r$ & جيد ( · r درجة فأكثر) \\
\hline $1 \ldots$ & r... & 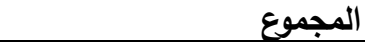 \\
\hline
\end{tabular}

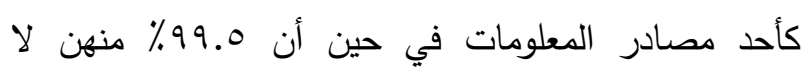

تثير نتائج جدول (^) إلى أن 0.0٪ ٪ من المبحوثات

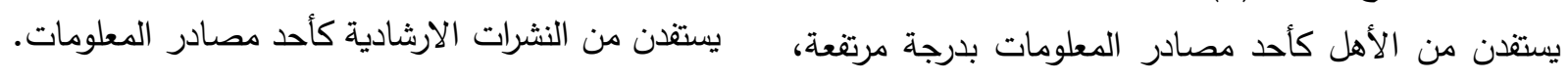
كما أن 79.0\% من العينة استفادتهن متوسطة من الجيران

جدول ^. توزيع المحوثات تنازليا وفقا للنسبة المئوية لارجة الاستفادة المرتفعة من مصادر المعلومات

\begin{tabular}{|c|c|c|c|c|c|c|}
\hline \multicolumn{6}{|c|}{ درجة الاستفادة } & \multirow[t]{3}{*}{ مصادر المعلومات } \\
\hline \multicolumn{2}{|c|}{ لا استفيد } & \multicolumn{2}{|c|}{ متوسطة } & \multicolumn{2}{|c|}{ مرتفعة } & \\
\hline$\%$ & عدد & $\%$ & عدد & $\%$ & عدد & \\
\hline. .0 & 1 & $0 \leqslant$ & 1.1 & $\varepsilon 0.0$ & 91 & الأهل \\
\hline$\varepsilon .0$ & 9 & 01.0 & $1 . r$ & $\varepsilon \varepsilon$ & 从 & الطبيب \\
\hline «.० & 9 & Tr & $M \varepsilon$ & rT.o & TV & التليفزيون \\
\hline V.o & 10 & 79.0 & זrו & r & or & الاصدقاء \\
\hline ir & $r \varepsilon$ & 79.0 & 149 & 11.0 & rv & الجيران \\
\hline$\varepsilon v$ & $9 \varepsilon$ & 0 . & $1 \ldots$ & r & 7 & الراديو الريو \\
\hline 71.0 & $1 \pi v$ & rq & 01 & Y.O & 0 & الجرائد والمجلات \\
\hline 01.0 & $1 . r$ & $\varepsilon \wedge$ & 97 &. .0 & 1 & الرائدة الرنفية \\
\hline 99.0 & 199 & . & . &. .0 & 1 & النشرات الآرشادية \\
\hline $9 \Lambda$ & 197 & r & $\varepsilon$ & . & . & الاجتماعات الارشادية \\
\hline
\end{tabular}


جدول 9. توزيع المبحوثات وفقا لإجمالي الارجة المعبرة عن استجاباتهن لعبارات الممارسات السلبية المتعلقة بطرق وأماكن حفظ وتخزين المواد الغذائية

\begin{tabular}{|c|c|c|}
\hline$\%$ & العدد & الفئات \\
\hline $0 .$. & 1. & ضعيف ( 19 > > \\
\hline$\varepsilon \varepsilon .0$ & 19 & متوسط (' צr > \\
\hline $0 . .0$ & 1.1 & جيد (سب فأكثر) \\
\hline $1 \ldots$ & r... & المجموع \\
\hline
\end{tabular}

وتثير نتائج جدول (·) إلى أن rال الم مبحوثة من العينة ذكرن انهن يؤدين بثكل دائم ممارسة (لا أقوم بالتقليب المستمر للحبوب المخزنة للتخلص من الحشرات) بنسبة 7ه \%، بينما بلغ عدد من يقمن بآداء ممارسة (لا أخزن القصح والثعير على أرفف عالية عن الأرض) بشكل دائم 07

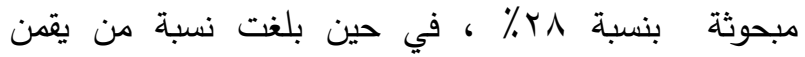
بممارسة (أخزن التوابل مدة طويلة في دولاب المطبخ) بثكل دائم r ب فقط منهن.
ثانيا: المستوى العام لبعض الممارسات اليومية السلبية لمبحوثات بمنطقة البحث

لقياس المستوى العام لبعض الممارسات اليومية السلبية

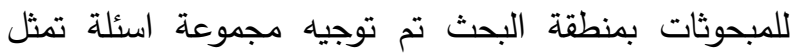
بعض الممارسات السلبية اليومية للمبحوثات في المحاور

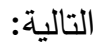
( ) طرق وأماكن حفظ وتخزين المواد الغذائية.

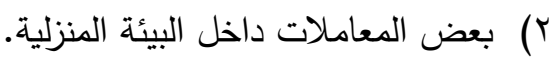
r) التخلص من المخلفات المنزلية والحيوانات النافقة. 1- بعض الممارسات السلبية المتعقة بطرق وأماكن حفظ وتخزين المواد الغذائية تثير نتائج جدول (9) أن اكثر من نصف العينة بنسبة

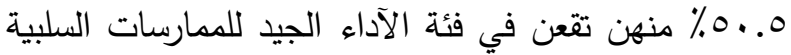
المتعلقة بطرق وأماكن حفظ وتخزين المواد الغذائية ، كما أن

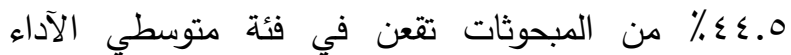

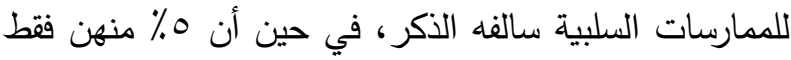
تقعن في فئة الآداء الضعيف للممارسات السلبية سالفة فانة الذكر .

جدول • 1 ـ توزيع المبحوثات تنازليا وفقا للنسبة المئوية لارجة دوام استجاباتهن لعبارات الممارسات السلبية المتعلقة بطرق وأماكن حفظ وتخزين المواد الغذائية

\begin{tabular}{|c|c|c|c|c|c|c|}
\hline \multicolumn{6}{|c|}{ السلوك } & \multirow[t]{3}{*}{ العبارات } \\
\hline \multicolumn{2}{|c|}{ نادرا } & \multicolumn{2}{|c|}{ احيانا } & \multicolumn{2}{|c|}{ دائما } & \\
\hline$\%$ & عدد & $\%$ & عدد & $\%$ & عدد & \\
\hline 11.0 & Tr & rT.O & 70 & 07 & 114 & لا أقوم بالتقليب المستمر للحبوب المخزنة للتخلص من الحشرات \\
\hline 19 & ru & or & 1.7 & rA & 07 & لا أخزن الققح والشعير \\
\hline$\leqslant 1.0$ & Ar & 0. & $1 \cdots$ & 1.0 & IV & أحفظ الطعام المتبقى فى حلل ألكومنيوم فى الثناجة \\
\hline $0 \xi$ & $1 \cdot 1$ & «1 & At & ० & 1. & 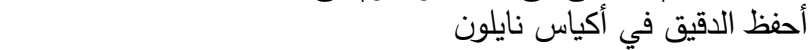 \\
\hline ri.0 & זד & 7.0 & ITV & 0 & 1. & لا اضيف قطرات من الليمون على الجين القرش لزيادة مدة حفظها \\
\hline VA.० & $10 \mathrm{~V}$ & 17.0 & זr & 0 & 1. & أغسل آلغلة في الترعة قبل طنها \\
\hline 07 & 114 & $\varepsilon$. & A. & $\varepsilon$ & $\wedge$ & أخزن السمنة فى برطمانات بلاستيك \\
\hline Or.o & $1 . \mathrm{V}$ & $\varepsilon r .0$ & 10 & $\varepsilon$ & $\wedge$ & استعمل ورق الجرائد لامتصاص زيت القلى من البطاطس والأسماك \\
\hline 71 & MT & r..0 & $\mathrm{vr}$ & r.o & o & أحفظ الخضروات والسندوتشات فى ورق جرائد \\
\hline$v 1.0$ & $1 \leqslant r$ & rч & or & 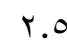 & ० & أستعمل المبيدات (البودرة) فى حفظ الحبوب والبطاطس \\
\hline 71.0 & $1 \pi \mathrm{V}$ & r9.0 & 09 & r & $\varepsilon$ & لا أهتم بتقليب الخضروات أثناء تجفيفها \\
\hline 01 & 117 & $\varepsilon$. & A. & r & $\varepsilon$ & أخزن التوابل مدة طويلة فى دولاب التطبخ \\
\hline$\Lambda \varepsilon$ & 171 & $1 \leqslant .0$ & rq & 1.0 & r & أخزن الغلة والأرز في عبوات المبيد الفارغة \\
\hline
\end{tabular}


كما تشير نتائج جدول (Y I (Y) إلى أن IVI مبحوثة من العينة ذكرن انهن يؤدين بثكل دائم ممارسة (لا أهتم بنظافة المطبخ وغسل الأواني والأدوات المستعملة يومياً) بنسبة

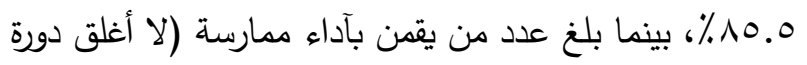

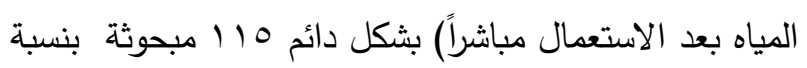

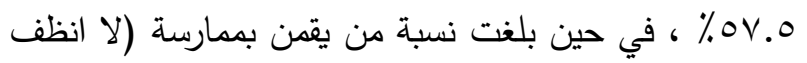

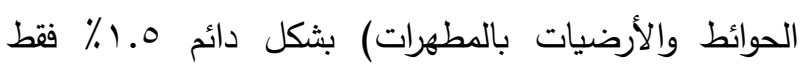

منهن. r- الممارسات السلبية المتعلقة بالتخلص من المخلفات المنزلية والحيوانات النافقة تشير نتائج جدول (rا) إلى أن سع \% من المبحوثات تقعن في فئة الآداء الجيد للممارسات السلبية المتعلقة بالتخلص من المخلفات المنزلية والحيوانات النافقة ، كما أن ــ ٪ منهن تقعن في فئة متوسطي الآداء للممارسات

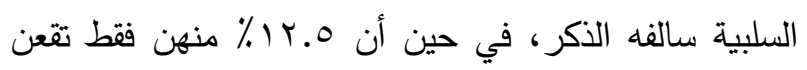
في فئة الآداء الضعيف للممارسات السلبية سالفة الذكر . r- الممارسات السلبية المتعلقة ببعض المعاملات داخل البيئة المنزلية

تثير نتائج جدول (11) أن اكثر من نصف العينة بنسبة \% \% منهن تقعن في فئة الآداء الجيد للممارسات السلبية المتعلقة ببعض المعاملات داخل البيئة المنزلية ، كما أن بـ \% من المبحوثات تقعن في فئة متوسطي الآداء

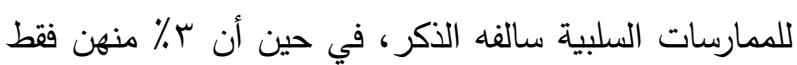
تقعن في فئة الآداء الضعيف للممارسات السلبية سالفة

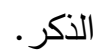

جدول 11. توزيع المبحوثات وفقا لإجمالي الدرجة المعبرة عن استجاباتهن لعبارات الممارسات السلبية المتعلقة ببعض المعاملات داخل البيئة المنزلية

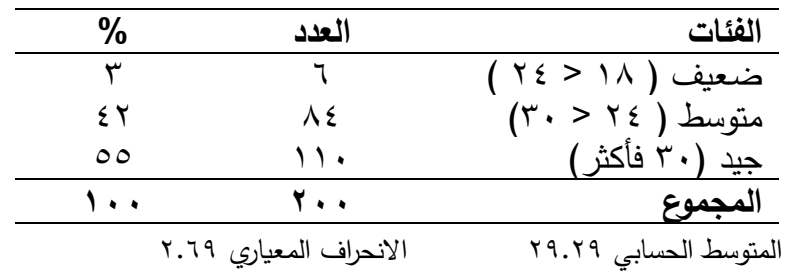

جدول r ا ـ توزيع المبحوثات تنازليا وفقا للنسبة المئوية لارجة دوام استجاباتهن لعبارات الممارسات السلبية المتعلقة ببعض المعاملات داخل البيئة المنزلية

\begin{tabular}{|c|c|c|c|c|c|c|}
\hline \multicolumn{6}{|c|}{ السلوك } & \multirow[t]{3}{*}{ 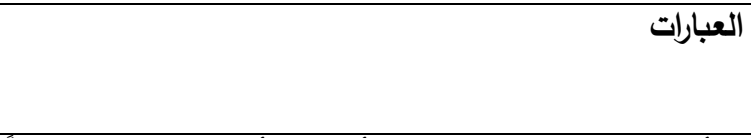 } \\
\hline \multicolumn{2}{|c|}{ 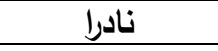 } & \multicolumn{2}{|c|}{ 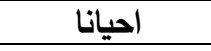 } & \multicolumn{2}{|c|}{ دائما } & \\
\hline$\%$ & عدد & $\%$ & عدد & $\%$ & عدد & \\
\hline$\varepsilon .0$ & 9 & $1 \cdot$ & $r \cdot$ & 10.0 & $|V|$ & لا أهتم بنظافة المطبخ وغسل الأوانى والأدِوات المستعملة يومياً \\
\hline ir & $r \leq$ & $r \cdot .0$ & 7) & $0 V .0$ & 110 & لا أغلق دورة المياه بعد الاستعمال مباشراً \\
\hline V & $1 \leq$ & $\varepsilon 9$ & $9 \wedge$ & $\varepsilon \varepsilon$ & $\wedge \wedge$ & انظف الحظيرة بدون استخدام مطهرات \\
\hline $1 \leqslant .0$ & rq & or & $1 \cdot \varepsilon$ & rT.O & TV & لا أقوم بسد الثقوق والثقوب في الحوائط لمنع انتشار الحشرات \\
\hline$\varepsilon .0$ & 9 & $V \leqslant .0$ & $1 \leqslant 9$ & r) & $\varepsilon r$ & لا اقوم بتهوية فرش البيت يومياً \\
\hline $7 . .0$ & $|r|$ & 少 & Tr & 1.0 & iV & أترك الطيور تمشى فى البيت \\
\hline 19.0 & 189 & ร.० & 9 & 7 & Kr & أستخدم الفرن البلدي فى الخبيز فوق سطح المنزل \\
\hline 79 & $1 \% 1$ & ry & or & 0 & $1 \cdot$ & أستخدم لمبة الجاز وبها أقراص المبيد لطرد الناموس \\
\hline $0 \wedge$ & 117 & $r v$ & $\vee \leqslant$ & 0 & 1. & لا أقوم بنظافة الثارع أمام المسكن \\
\hline 01.0 & $11 \mathrm{~V}$ & rV.o & vo & $\varepsilon$ & $\wedge$ & أقوج بتظيف الحظيرة بدون استخدام ماء \\
\hline$V \varepsilon .0$ & $1 \leqslant 9$ & r..0 & $\varepsilon r$ & $\varepsilon$ & $\wedge$ & لا أخصص مكان لتخزين السماد والمبيد فى البيت \\
\hline$\wedge \vee .0$ & 1Vo & $1 \cdot$ & r. & r.० & o & أكسح الترنشات المنزلية فى الترعة \\
\hline TV & $1 \pi \varepsilon$ & 1.0 & זי & 1.0 & $r$ & لا انظف الحوائط والأرضيات بالمطهرات \\
\hline
\end{tabular}



سميرة احمد قنديل وآخرون: وعي الريفيات بمخاطر بعض الممارسات اليومية السلبية على صحة الإنسان...

جدول س ا ا.توزيع المبحوثات وفقا لإجمالي الارجة المعبرة عن استجاباتهن لعبارات الممارسات السلبية المتعلقة بالتخلص من المن المخلفات المنزلية وإلحيوانات النافقة

\begin{tabular}{|c|c|c|}
\hline$\%$ & العدد & الفئات \\
\hline $1 \% .0$ & TO & ضعيف (Y > > ) \\
\hline$\varepsilon \varepsilon .0$ & 19 & متوسط ( \\
\hline$\varepsilon r .$. & At & جيد (كَ' فأكثر ) \\
\hline $1 \ldots$ & r.. & المجموع \\
\hline
\end{tabular}

والحيوانات فرشة للأرض وعمل قربة لخض اللبن) بشكل دائم

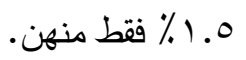

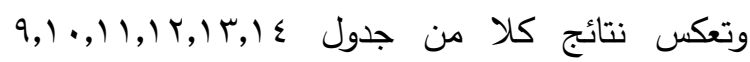

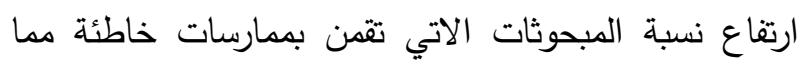
يستلزم المزيد من الجهود الارشادية للعمل على تصحيح

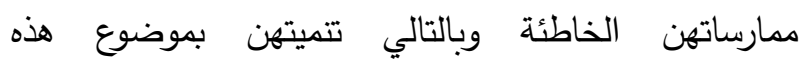
الممارسات.
وتثير نتائج جدول (ع () إلى أن ح1 مبحوثة من العينة

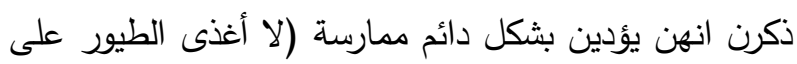

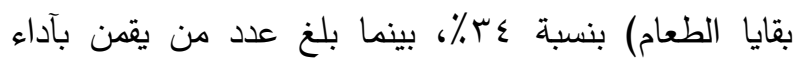

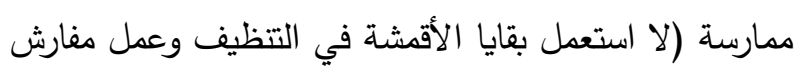

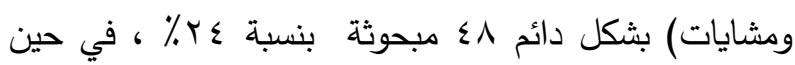
بلغت نسبة من يقمن بممارسة (لا أستعمل جلود الأغنام

جدول \& ا. توزيع المبحوثات تنازليا وفقا للنسبة المئوية لارجة دوام استجاباتهن لعبارات الممارسات السلبية المتعلقة بالتخلص من المخلفات المنزلية والحيوانات النافقة

\begin{tabular}{|c|c|c|c|c|c|c|}
\hline \multicolumn{6}{|c|}{ السلوك } & \multirow[t]{3}{*}{ 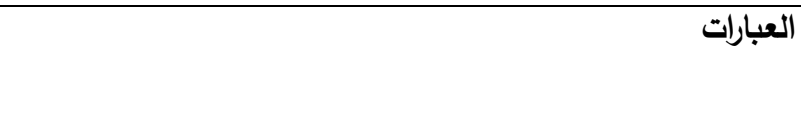 } \\
\hline \multicolumn{2}{|c|}{ نادرا } & \multicolumn{2}{|c|}{ احيانا } & \multicolumn{2}{|c|}{ دائما } & \\
\hline$\%$ & عدد & $\%$ & عدد & $\%$ & عدد & \\
\hline r..0 & $\varepsilon r$ & $\varepsilon \varepsilon .0$ & 19 & Tะ & 71 & لا أغذى الطيور على بقايا الطعام \\
\hline$r \cdot .0$ & 71 & $\leqslant 0.0$ & 9) & TE & $\varepsilon \wedge$ & لا استعمل بقايا الأقمشة فى التتظيف وعمل مفارش ومشايات \\
\hline Tr & $7 \varepsilon$ & or & $1 \cdot \varepsilon$ & 17 & Tr & أحرق القمامة أمام البيت لعمل دخان لطرد الناموس \\
\hline r. 1.0 & r & or & 1.7 & 10.0 & m & لا أَقوم ببيع زجاجات الزيت الفارغة وعلب الصفيح لتاجر الخردة \\
\hline$\varepsilon$. & $\Lambda$. & 0 or.o & $1 \cdot V$ & 7.0 & IT & أستعمل روث الحيوانات وزرق الطيور فى عمل سماد بلدي \\
\hline$\Lambda_{7}$ & IVT & 9.0 & 19 & £.0 & 9 & لا أقوم بعمل صابون من بقايا الزيت بعد استعماله \\
\hline$\leqslant \vee$ & $9 \leq$ & $\leqslant 9.0$ & 99 & r.० & $\checkmark$ & أستعمل العبوات البلاستيكية الفارغة كأوانى لشرب الطيور \\
\hline$\wedge \varepsilon .0$ & 179 & $1 Y .0$ & ro & r & 7 & أقوم بكسح مياه الغسيل فى الترعة \\
\hline 90 & 19. & r & $\varepsilon$ & r & 7 & ارمى السرنجات والنفايات الطبية فى الترعة \\
\hline 10.0 & $|V|$ & ir & $r \varepsilon$ & r.o & ○ & أتخلص من الحيوانات والطيور الميتة برميها فى الترعة \\
\hline 9. & $1 \wedge$. & $V .0$ & 10 & Y.० & ○ & أتخلص من بقايا الزجاج المكسور فَى الترعة \\
\hline 00 & 11. & $\leqslant r .0$ & Av & 1.0 & r & لا استععل بقايا الورق والكرتون كفرشة فى المطبخ لتنظيف \\
\hline 10 & iv. & $1 r .0$ & rV & 1.0 & r & لخض أللبن جلود الأغنام والحيوانات فرشة للأرض وعمل قربة \\
\hline
\end{tabular}




$$
\text { مجلة الإسكندرية للتبادل العلمى - (مجلد \& العدد r) ابريل - يونيو ابr r }
$$

جدول ه 1 ـ توزيع المبحوثات وفقا لإجمالي الارجة المعبرة عن

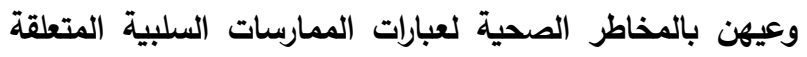
بطرق وأماكن حفظ وتخزين المواد الغذائية على الإنسان

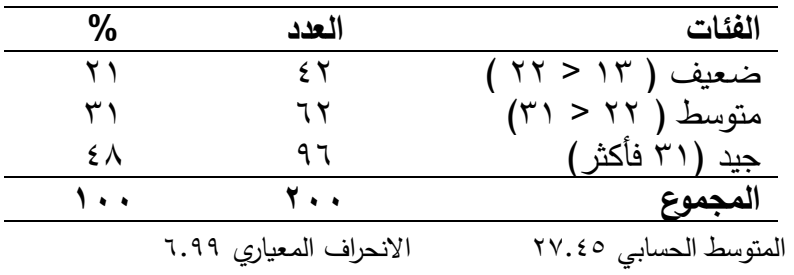

كما تشير نتائج جدول (7 ا) إلى أن 17 (1) مبحوثة من العينة لايهن وعي بالمخاطر الصحية على الإنسان المصاحبة لآداء ممارسة (أخزن الغلة والأرز في عبوات

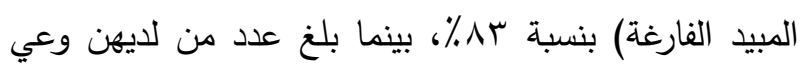
بالمخاطر الصحية على الإنسان المصاحبة لآداء ممارسة (استعمل ورق الجرائد لامتصاص زيت القلي من البطاطس

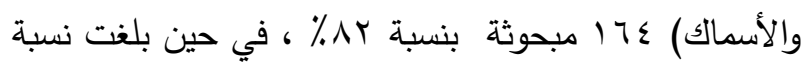
من لايهن وعي بالمخاطر الصحية على الإنسان المصاحبة لآداء ممارسة (لا أخزن القمح والثعير على أرفف عالية عن إن الثان الأرض) v \% فقط منهن.
ثالثا: المستوى العام لوعي المبحوثات بمخاطر بعض الممارسات اليومية السلبية على الإنسان بمنطقة البحث 1 - وعي المبحوثات بالمخاطر الصحية للممارسات السلبية المتعلقة بطرق وأماكن حفظ وتخزين المواد الغذائية على الإنسان

تثير نتائج جدول (10) إلى أن قرابة نصف العينة بنسبة ^^ء تقعن في فئة الوعي الجيد بالمخاطر الصحية على الإنسان المصاحبة لآداء بعض الممارسات السلبية

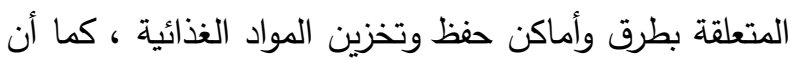
اس\% منهن تقعن في فئة متوسطي الوعي بالمخاطر الصحية على الإنسان المصاحبة لآداء بعض الممارسات السلبية سالفه الذكر، في حين أن اب ٪ منهن فقط تقعن في لإنسان فئة الوعي الضعيف بالمخاطر الصحية على الإنسان المصاحبة لآداء بعض الممارسات السلبية سالفة الذكر .

جدول ا ا ـ توزيع المبحوثات تنازليا وفقا للنسبة المئوية لارجة وعيهن بالمخاطر الصحية لعبارات الممارسات السلبية المتعلقة

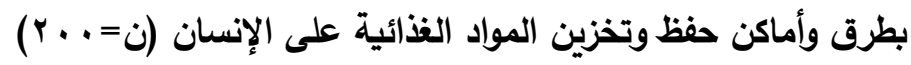

\begin{tabular}{|c|c|c|c|c|c|c|}
\hline \multicolumn{6}{|c|}{ مخاطر السلوك على صحة الإنسان } & \multirow[t]{3}{*}{ 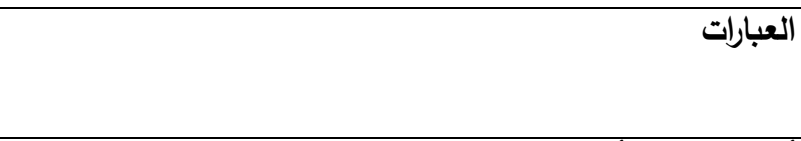 } \\
\hline \multicolumn{2}{|c|}{ ل لاعرف } & \multicolumn{2}{|c|}{ ע } & \multicolumn{2}{|c|}{ نعو } & \\
\hline$\%$ & عدد & $\%$ & عدد & $\%$ & عدد & \\
\hline 1.0 & $\mathrm{r}$ & 10.0 & ए। & NT & 177 & أخزن الغلة والأرز فى عبوات المبيد الفارغة \\
\hline r & $\varepsilon$ & 17 & 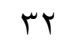 & At & $17 \leq$ & استعمل ورق الجرائد لامتصاص زبت القلى من البطاطس والأسماك \\
\hline r & 7 & $1 \vee .0$ & ro & $\vee 9.0$ & 109 & لا أهتم بتقليب الخضروات أثناء تجفيفها \\
\hline 1.0 & r & r५.0 & or & VY & $1 \leq \varepsilon$ & أخزن التوابل مدة طويلة في دولاب المطبخ \\
\hline 1 & r & ru & 07 & $v_{1}$ & $1 \leqslant r$ & أحفظ الخضروات والسندوتثات فى ورق جرائد \\
\hline 1 & r & $r \cdot .0$ & 71 & 71.0 & IrV & أخزن السمنة في برطمانات بلاستيك \\
\hline r & 7 & rq & $0 \wedge$ & $7 \wedge$ & דיד & أغسل الغلة فى الترعة قبل طحنها \\
\hline r & $\varepsilon$ & $\leqslant 0.0$ & 91 & OY.O & 1.0 & أحفظ الدقيق فى أكياس نايلون \\
\hline r & $\varepsilon$ & $\leqslant \vee .0$ & 90 & $0 . .0$ & $1 \cdot 1$ & أحفظ الطعام المتبقى فى حلل ألومنيوم فى الثلاجة \\
\hline 1.0 & r & 09 & 111 & r..० & $\vee q$ & أستعمل المبيدات (البودرة) في حفظ الحبوب والبطاطس \\
\hline$\varepsilon$ & $\wedge$ & VV.O & 100 & 11.0 & rV & لا أقوم بالتقليب المستمر للحبوب المخزنة للتخلص من الحشرات \\
\hline$\varepsilon .0$ & 9 & $\vee 9.0$ & 109 & 17 & re & لا اضيف قطرات من الليمون على الجبن القريش لزيادة مدة حفظها \\
\hline 1.0 & r & 91.0 & וN & V & $1 \varepsilon$ & لا أخزن القدح والشعير على أرفف عالية \\
\hline
\end{tabular}


جدول V I . توزيع المبحوثات وفقا لإجمالي الدرجة المعبرة عن وعيهن بالمخاطر الصحية لعبارات الممارسات السلبية المتعلقة

\begin{tabular}{|c|c|c|}
\hline & \multicolumn{2}{|c|}{ بعض المعاملات داخل المنزل على الإنسان } \\
\hline$\%$ & العدد & الفئات \\
\hline 0.0 & 11 & ضعيف ( . ro > ) \\
\hline Ar.. & $17 \varepsilon$ & متوسط (م0 > > . r) \\
\hline $1 Y .0$ & ro & جيد (·س فأكثر) \\
\hline $1 \cdots$ & r.. & المجموع \\
\hline
\end{tabular}

وتشير نتائج جدول (1) إلى أن بو إ مبحوثة من العينة لديهن وعي بالمخاطر الصحية على الإنسان المصاحبة لآداء ممارسة (أكسح الترنشات المنزلية في الترعة) بنسبة ه.97\%، بينما بلغ عدد من لديهن وعي بالمخاطر الصحية على الإنسان المصاحبة لآداء ممارسة (لا أقوم

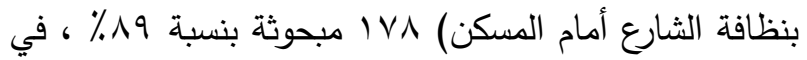
حين بلغت نسبة من لايهن وعي بالمخاطر الصحية على الإنسان المصاحبة لآداء ممارسة (انظف الحظيرة بدون استخدام مطهرات) ؛ ٪ فقط منهن. r - وعي المبحوثات بالمخاطر الصحية للممارسات السلبية المتعقة ببعض المعاملات داخل المنزل على الإنسان

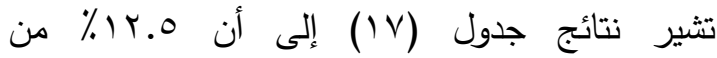
المبحوثات تقعن في فئة الوعي الجيد بالمخاطر الصحية على الإنسان المصاحبة لآداء بعض الممارسات السلبية

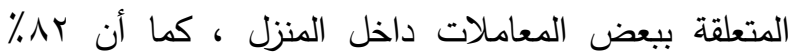
منهن تقعن في فئة متوسطي الوعي بالمخاطر الصحية على الإنسان المصاحبة لآداء بعض الممارسات السلبية سالفه الذكر، في حين أن 0.0\% منهن فقط تقعن في فئة الوعي الضعيف بالمخاطر الصحية على الإنسان المصاحبة لآداء بعض الممارسات السلبية سالفة الذكر .

جدول ^1. توزيع المبحوثات تنازليا وفقا للنسبة المئوية لارجة وعيهن بالمخاطر الصحية لعبارات الممارسات السلبية المتعلقة ببعض المعاملات داخل المنزل على الإنسان

\begin{tabular}{|c|c|c|c|c|c|c|}
\hline \multicolumn{6}{|c|}{ مخاطر السلوك على صحة الإنسان } & \multirow[t]{3}{*}{ 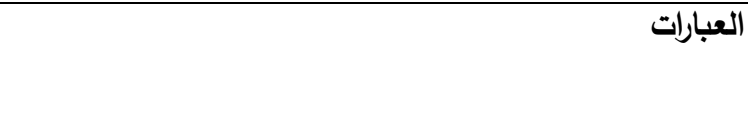 } \\
\hline \multicolumn{2}{|c|}{ لا لاعزف } & \multicolumn{2}{|c|}{$y$} & \multicolumn{2}{|c|}{ 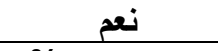 } & \\
\hline$\%$ & عدد & $\%$ & عدد & $\%$ & عدد & \\
\hline$r$ & 7 &. .0 & 1 & 97.0 & 194 & أكسح الترنشات المنزلية في الترعة \\
\hline $1 . .0$ & (1) &. .0 & 1 & 19 & IVA & لا أقوم بنظافة الثارع أمام المسكن \\
\hline 11 & דy & r & $\varepsilon$ & $\wedge$. & 17. & لا انظف الحوائط والآرضيات بالمطهرات \\
\hline rV & $v \leqslant$ & 1 & r & Tr & ITE & لا أخصص مكان لتخزين السماد والمبيد في البيت \\
\hline$\varepsilon r$ & $\wedge 7$ & 1 & r & 07 & $11 \mathrm{r}$ & أقوم بتظيف الحظيرة بدون استخدام ماء \\
\hline$\varepsilon$. & ᄉ. & 0 & 1. & 00 & 11. & أستخدم الفرن البلدي فى الخبيز فوق سطح المنزل \\
\hline זיד & $1 \times 4$ & 9.0 & 19 & YV.O & 00 & أترك الطيور تمشى في البيت \\
\hline$V \varepsilon$ & $1 \leqslant 1$ & $1 . .0$ & r) & 10.0 & ri & أستخدم لمبة الجاز وبها أقراص المبيد لطرد الناموس \\
\hline rt & $7 \varepsilon$ & 00 & 11. & ir & $r \tau$ & لا أغلق دورة المياه بعد الاستعمال مباشراً \\
\hline r9.० & 09 & Tr & ITE & 1.0 & iv & لا أقوم بسد الثقوق والثقوب فى الحوائط لمنع انتشار الحشراتٍ \\
\hline 9.0 & 19 & 10 & ive & 0.0 & 11 & لا أهتم بنظافة المطبخ وغسل الآوأوانى والأدوات المستعملة يومياً \\
\hline iv & $r \varepsilon$ & $\vee q$ & 101 & $\varepsilon$ & $\wedge$ & لا اقوم بتهوية فرش الَّ \\
\hline $1 . .0$ & (1) & 10.0 & $1 \mathrm{VI}$ & $\varepsilon$ & $\Lambda$ & انظف الحظيرة بدون استخدام مطهرات \\
\hline
\end{tabular}




$$
\text { مجلة الإسكندرية للتبادل العلمى - (مجلد \& العدد r) ابريل - يونيو ابr r }
$$

جدول 9 ا.توزيع المبحوثات وفقا لإجمالي الدرجة المعبرة عن

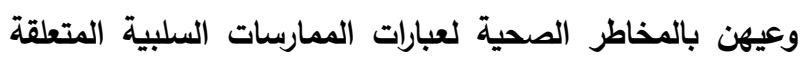
بالتخلص من المخلفات المنزلية والحيوانات النافقة على الإنسان

\begin{tabular}{|c|c|c|}
\hline$\%$ & العدد & الفئات \\
\hline YY.O & $\leqslant 0$ & ضعيف ( . r > Y ) \\
\hline $0 \wedge .0$ & $11 \mathrm{~V}$ & متوسط ( 0 > > . \\
\hline $19 .$. & r人 & جيد (· ب فأكثر) \\
\hline $1 \ldots$ & $r \ldots$ & المجموع \\
\hline
\end{tabular}

كما تشير نتائج جدول (·r) إلى أن \&9 19 مبحوثة من

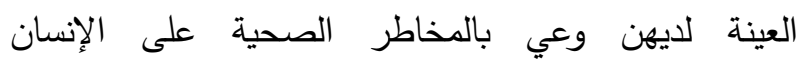
المصاحبة لآداء ممارسة (ارمى السرنجات والنفايات الطبية

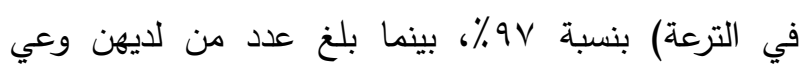

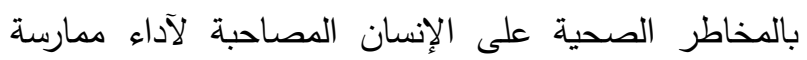

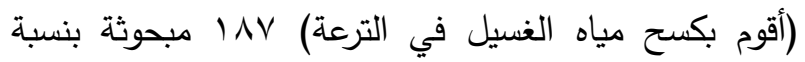
ه. \% \% ، في حين بلغت نسبة من لديهن وعي بالمخاطر الصحية على الإنسان المصاحبة لآداء ممارسة (أستعمل لئل

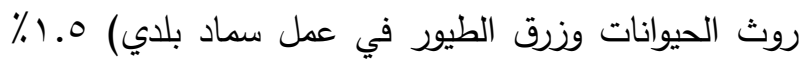
فقط منهن. r- وعي المبحوثات بالمخاطر الصحية للممارسات السلبية المتعلقة بالتخلص من المخلفات المنزلية والحيوانات النافقة على الإنسان تثير نتائج جدول (9 (1) إلى أن 9 (1\% من المبحوثات تقعن في فئة الوعي الجيد بالمخاطر الصحية على الإنسان المصاحبة لآداء بعض الممارسات السلبية المتعلقة بالتخلص بله

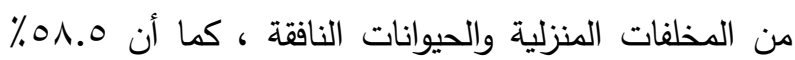
منهن تقعن في فئة متوسطي الوعي بالمخاطر الصحية على الإنسان المصاحبة لآداء بعض الممارسات السلبية سالفه

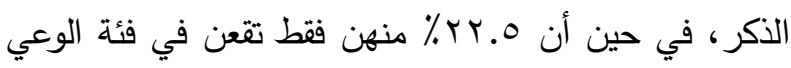
الضعيف بالمخاطر الصحية على الإنسان المصاحبة لآداء بعض الممارسات السلبية سالفة الذكر .

جدول · r .توزيع المبحوثات تنازليا وفقا للنسبة المئوية لارجة وعيهن بالمخاطر الصحية لعبارات الممارسات السلبية المتعلقة بالتخلص من المخلفات المنزلية والحيوانات النافقة على الإنسان

\begin{tabular}{|c|c|c|c|c|c|c|}
\hline \multicolumn{6}{|c|}{ مخاطر السلوك على صحة الإنسان } & \multirow[t]{3}{*}{ 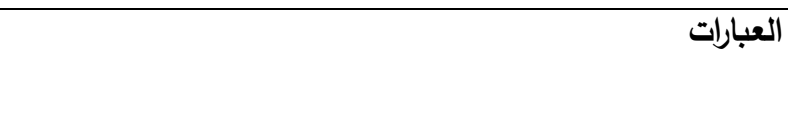 } \\
\hline \multicolumn{2}{|c|}{ لا لا اعرف } & \multicolumn{2}{|c|}{ ע } & \multicolumn{2}{|c|}{ نعم } & \\
\hline$\%$ & عدد & $\%$ & عدد & $\%$ & عدد & \\
\hline r.o & 0 & .0 & 1 & $9 V$ & $19 \varepsilon$ & ارمى السرنجات والنفايات الطبية فى الترعة \\
\hline$\varepsilon$ & $\Lambda$ & r.o & 0 & 94.0 & $11 \mathrm{~V}$ & أقوم بكسح مياه الغسيل في الترعة \\
\hline 0.0 & 11 & $\varepsilon .0$ & 9 & 9. & $1 \wedge$. & أتخلص من بقايا الزجاج الدكسور فى الترعة \\
\hline 11.0 & rv &. .0 & 1 & $\wedge$ & 174 & أتخلص من الحيوانات والطيور الميتة برميها في الترعة \\
\hline 01.0 & $1 \cdot r$ & r & rt & ro.0 & v) & لا استعمل بقايا الورق والكرتون كفرشة فى المطبخ لتنظيف \\
\hline$\varepsilon \vee .0$ & 90 & r.o & $T V$ & 19 & rᄉ & أحرق القمامة أمام البيت لعمل دخان لطرد الناموس \\
\hline$\uparrow \wedge .0$ & irV & 19 & r的 & M.O & ro & أستعمل العبوات البلاستيكية الفارغة كأوانى لشرب الطيور \\
\hline rq & $0 \wedge$ & $7 \varepsilon$ & IrA & $\checkmark$ & $1 \varepsilon$ & لا أقوم بعمل صابون من بقايا الزيت بعد استعماله \\
\hline$\leqslant 0.0$ & 91 & $\varepsilon \wedge$ & 97 & 7.0 & 14 & لا استعمل بقايا الأقَمشة فى التنظيف وعمل مفارِ ومشايات \\
\hline$V_{7}$ & 104 & Y) & $\varepsilon r$ & r & 7 & لخض أستعمل جلود الأغنام والحيوانات فرشة للأرض وعمل قربة \\
\hline$\leqslant \vee$ & $9 \leq$ & $0 . .0$ & $1 \cdot 1$ & Y.० & 0 & لا أغذى الطيور على بقايا الطعام \\
\hline rq & $\vee \wedge$ & 09 & 111 & r & $\varepsilon$ & لا أقوم ببيع زجاجات الزيت الفارغة وعلب الصفيح لتاجر الخردة \\
\hline tr & $0 \leqslant$ & $\vee 1.0$ & $1 \leq r$ & 1.0 & r & أستعمل روث الحيوانات وزرق الطيور في عمل سماد بلدي \\
\hline
\end{tabular}


جدول اY . توزيع المبحوثات وفقا لإجمالي الدرجة المعبرة عن مجموع محاور وعيهن بمخاطر بعض الممارسات السلبية على صحة الإنسان

\begin{tabular}{|c|c|c|}
\hline$\%$ & العدد & 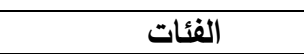 \\
\hline TY.O & ¿0 & ضعيف ( \\
\hline r & or & 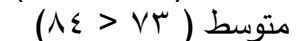 \\
\hline 01.0 & $1 . r$ & جيد (ع أ فأكثر) \\
\hline $1 \cdots$ & r.. & المجموع \\
\hline
\end{tabular}

1- اقتران مستوي وعي المبحوثات بمخاطر بعض

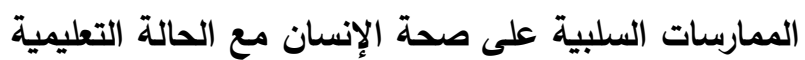
للمبحوثة : وتثير نتائج جدول (Yr) الي وجود علاقة اقتران بين كلا من الحالة التعليمية للمبحوثة و مستوي الوعي بالمخاطر الصحية لبعض الممارسات السلبية على الإنسان حيث بلغت قيمة كاب سا . به درجة وهي قيمة معنوية عند المستوى الاحتمالي ا ... مما يستلزم من المسئولين عند الحاجة لرفع مستوى الوعي بالمخاطر الصحية على الإنسان المصاحبة لآداء بعض الممارسات السلبية الاهتمام بالحالة التعليمية للمبحوثات بتوجيه برامج ارشادية تتموية تعليمية بمنطقة البحث.

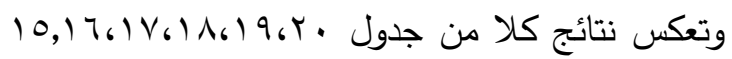
ارتفاع نسبة المبحوثات الاتي لديهن وعي بين المتوسط والمنخفض بالمخاطر الصحية المصاحبة لآداء بعض الممارسات الخاطئة مما يستلزم المزيد من الجهود الارشادية للعمل على رفع مستوى وعيهن بتلك المخاطر موضوع الدراسة.

رابعا: العلاقات الارتباطية بين كل من مستوى وعي المبحوثات العام بمخاطر بعض الممارسات اليومية السلبية على صحة الإنسان من جهة وكل من المتغيرات المستقلة المدروسة من جهة اخرى

تشير نتائج جدول (Y) إلى أن اكثر من نصف العينة بنسبة 01.0\% منهن تقعن في فئة اجمالي الوعي الجيد بالمخاطر الصحية على الإنسان المصاحبة لآداء المبحوثات

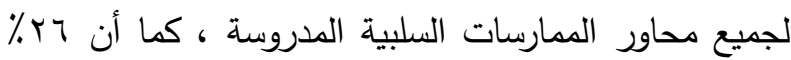
منهن تقعن في فئة متوسطي اجمالي الوعي بالمخاطر الصحية على الإنسان المصاحبة لآداء المبحوثات لجميع

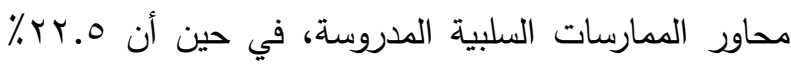
منهن فقط تقعن في فئة اجمالي الوعي الضعيف بالمخاطر

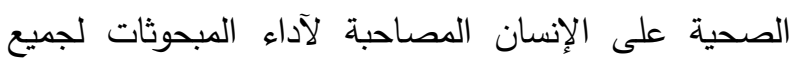
محاور الممارسات السلبية المدروسة.

جدول r r.توزيع المبحوثات تبعا لمستوي وعيهن بمخاطر بعض الممارسات السلبية على صحة الإنسان والحالة التعليمية المبحوثة

\begin{tabular}{|c|c|c|c|c|c|c|c|c|}
\hline \multirow{2}{*}{\multicolumn{2}{|c|}{ المجموع }} & \multicolumn{6}{|c|}{ مستوي وعى المبحوثات بمخاطر بعض الممارسات السلبية على صحة } & \multirow[t]{3}{*}{ لالمبحوثة التعليمية } \\
\hline & & \multicolumn{2}{|c|}{ جيد } & \multicolumn{2}{|c|}{ متوسط } & \multicolumn{2}{|c|}{ ضعيف } & \\
\hline$\%$ & عدد & $\%$ & عدد & $\%$ & عدد & $\%$ & علد & \\
\hline r..0 & «1 & 0 & 1. & 7.0 & $1 \pi$ & 9 & 11 & لا تقرأ ولا تكتب \\
\hline $1 \leqslant$ & rی & $\varepsilon$ & $\wedge$ & 0.0 & 11 & $\varepsilon .0$ & 9 & تقرأ وتكتب \\
\hline r.o & 0 & 1.0 & r & 1 & r & . & . & الشهادة الابتدائية \\
\hline 19.0 & rq & $\vee .0$ & 10 & 0 & 1. & $\mathrm{v}$ & $1 \varepsilon$ & الشهادة الاعدادية \\
\hline rV.o & vo & rA & 07 & $\wedge$ & 17 & 1.0 & r & الثهادة الثانوية ” \\
\hline 7 & ir & 7 & ir & . & . & . & . & الثهادة الجامعية \\
\hline $1 \ldots$ & r.. & or & $1 \cdot \varepsilon$ & ז & or & rt & $\varepsilon \varepsilon$ & المجموع \\
\hline & & & & & & & $0 \wedge .11$ & كاץ \\
\hline
\end{tabular}




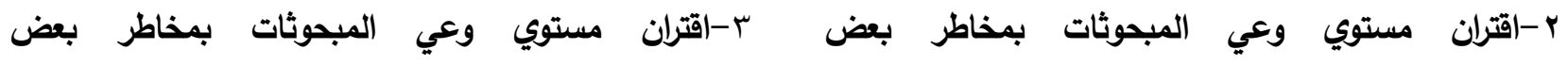
الممارسات السلبية على صحة الإنسان مع الحالة التعليمية الممارسات السلبية على صحة الإنسان مع الحالة الوظيفية

تشير نتائج جدول (؟ Y) إلي عدم وجود علاقة اقتران بين كلا من الحالة الوظيفية للمبحوثة و مستوي الوعي بالمخاطر الصحية لبعض الممارسات السلبية على الإنسان حيث بلغت قيمة كا Y TYV. ا الدرجة وهي قيمة غير معنوية

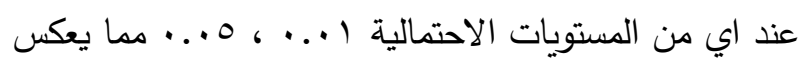

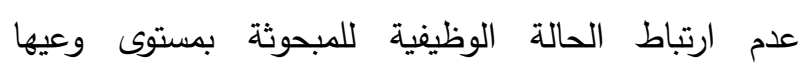
بالمخاطر الصحية سالفة الذكر.
تثير نتائج جدول (Yr) الي وجود علاقة اقتران بين كلا من الحالة التعليمية للزوج و مستوي الوعي بالمخاطر الصحية لبعض الممارسات السلبية على الإنسان حيث بلغت قيمة كاץ 77 ا ــأ درجة وهي قيمة معنوية عند المستوى الاحتمالي ا ... مما يستلزم من المسئولين عند الحاجة لرفع مستوى الوعي بالمخاطر الصحية على الإنسان المصاحبة لآداء بعض الممارسات السلبية الاهتمام بالحالة التعليمية

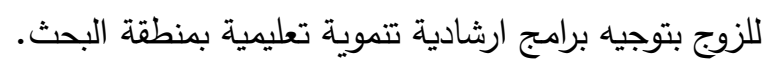

جذول سr. توزيع المبحوثات تبعا لمستوي وعيهن بمخاطر بعض الممارسات السلبية على صحة الإنسان و الحالة التعليمية

\begin{tabular}{|c|c|c|c|c|c|c|c|c|}
\hline \multirow{2}{*}{\multicolumn{2}{|c|}{ المجموع }} & \multicolumn{6}{|c|}{ مستوي وعى المبحوثات بمخاطر بعض الممارسات السلبية على صحة } & \multirow[t]{3}{*}{ الحالة التعليمية للزوج } \\
\hline & & \multicolumn{2}{|c|}{ جيد } & \multicolumn{2}{|c|}{ متوسيط } & \multicolumn{2}{|c|}{ ضعيف } & \\
\hline$\%$ & عدد & $\%$ & عدد & $\%$ & عدد & $\%$ & عدد & \\
\hline 10.0 & ri & r.o & $\bar{V}$ & $\varepsilon$ & $\Lambda$ & $\Lambda$ & 17 & لا يقرأ ولا يكتب \\
\hline $1 \leqslant .0$ & rq & $\varepsilon$ & $\wedge$ & 7 & ir & $\varepsilon .0$ & 9 & يقرأ وبكتب" . \\
\hline 1 & r & .0 & 1 &. .0 & 1 & . & . & الثهادة الابتدائية \\
\hline 17 & r & 0.0 & 11 & 0 & 1. & 0.0 & 11 & الثهادة الاعدادية \\
\hline$\varepsilon V .0$ & 90 & rr & 77 & $1 . .0$ & r & $\varepsilon$ & $\wedge$ & الثهادة الثانوبة \\
\hline 0.0 & 11 & 0.0 & 11 & . & . & . & . & الثهادة الجامعية \\
\hline \multirow[t]{2}{*}{$1 \ldots$} & r.. & or & $1 \cdot \varepsilon$ & r & or & rt & $\varepsilon \varepsilon$ & المجموع \\
\hline & & & $0 \leqslant$. & & & & & كاr \\
\hline
\end{tabular}

درجات حرية · 1 معنوي عند المستوي الاحتمالي ا...

جدول \& ب.توزيع المبحوثات تبعا لمستوي وعيهن بمخاطر بعض الممارسات السلبية على صحة الإنسان و الحالة الوظيفية

\begin{tabular}{|c|c|c|c|c|c|c|c|c|c|}
\hline \multirow{2}{*}{\multicolumn{2}{|c|}{ المجموع }} & \multicolumn{6}{|c|}{ مستوي وعى المبحوثات بمخاطر بعض الممارسات السلبية على صحة } & \multirow[t]{3}{*}{ الوظيفية } & \multirow[t]{3}{*}{ للمبحوثة الحالة } \\
\hline & & \multicolumn{2}{|c|}{ جيد } & \multicolumn{2}{|c|}{ متوسط } & \multicolumn{2}{|c|}{ ضعيف } & & \\
\hline$\%$ & عدد & $\%$ & عدد & $\%$ & عدد & $\%$ & عدد & & \\
\hline OV & $11 \varepsilon$ & $r 0.0$ & VI & $1 Y .0$ & ro & 9 & 11 & & تعمل \\
\hline$\varepsilon r$ & $\Lambda T$ & 17.0 & rr & $1 r .0$ & rV & rו & TY & & لا تعمل \\
\hline $1 \ldots$ & r.. & or & $\begin{array}{l}1 \cdot \varepsilon \\
11 . V\end{array}$ & $r y$ & or & rr & $\varepsilon \varepsilon$ & & 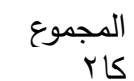 \\
\hline
\end{tabular}




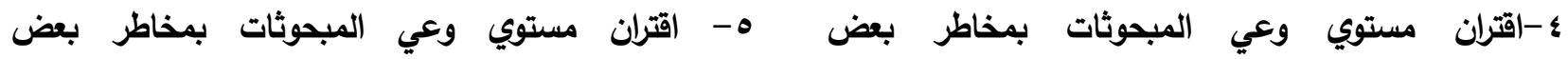

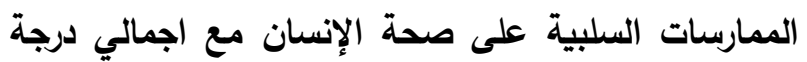
التعرض لمصادر المعلومات: الممارسات السلبية على صحة الإنسان مع مشاركة الزوج في الزراعة :

تشير نتائج جدول (Tr) إلي وجود علاقة اقتران بين كلا تشير نتائج جدول (ro) الي عدم وجود علاقة اقتران من اجمالي درجة التعرض لمصادر المعلومات و مستوي بين كلا من مشاركة الزوج في الزراعة ومستوي الوعي الوعي بالمخاطر الصحية لبعض الممارسات السلبية على بالمخاطر الصحية لبعض الممارسات السلبية على الإنسان

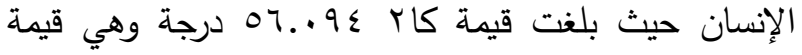
حيث بلغت قيمة كاب r90 . • 1 درجة وهي قيمة غير معنوية معنوية عند المستوى الاحتمالي هـ... مما يستلزم من المسئولين عند الحاجة لرفع مستوى الوعي بالمخاطر الصحية على الإنسان المصاحبة لآداء بعض الممارسات السلبية عند اي من المستويات الاحتمالية ا +.. ، 0... مما يعكس عدم ارتباط مشاركة الزوج في الزراعة بمستوى وعي المبحوثة بالمخاطر الصحية سالفة الذكر . الاهتمام بدرجة التعرض لمصادر المعلومات وذلك بتوجيه برامج ارشادية تتموية بمنطقة البحث. بـثمبه

جدول هץ. توزيع المبحوثات تبعا لمستوي وعيهن بمخاطر بعض الممارسات السلبية على صحة الإنسان و مثاركة الزوج

\begin{tabular}{|c|c|c|c|c|c|c|c|c|c|c|}
\hline \multirow{2}{*}{\multicolumn{2}{|c|}{ المجموع }} & \multicolumn{6}{|c|}{ مستوي وعى المبحوثات بمخاطر بعض الممارسات السلبية على صحة } & \multirow[t]{3}{*}{ فى } & \multirow[t]{3}{*}{ الزوج } & \multirow[t]{3}{*}{ مثاركة } \\
\hline & & \multicolumn{2}{|c|}{ حيد } & \multicolumn{2}{|c|}{ متوسط } & \multicolumn{2}{|c|}{ ضعيف } & & & \\
\hline$\%$ & عدد & $\%$ & عدد & $\%$ & عدد & $\%$ & عدد & & & \\
\hline 77 & ITr & $r \cdot .0$ & 71 & Yr & $\varepsilon \varepsilon$ & $1 \pi .0$ & $r V$ & & & تشارك \\
\hline$r \varepsilon$ & $7 \wedge$ & r..0 & $\varepsilon r$ & $\varepsilon$ & $\wedge$ & 1.0 & IV & & & لا تشارك \\
\hline $1 \ldots$ & $r \ldots$ & or & $\begin{array}{l}1 \cdot \varepsilon \\
1 . .\end{array}$ & rq & or & rr & $\varepsilon \varepsilon$ & & & 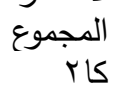 \\
\hline
\end{tabular}

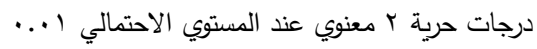

جدول \ب. توزيع المبحوثات تبعا لمستوي وعيهن بمخاطر بعض الممارسات السلبية على صحة الإنسان و اجمالي درجة التعرض لمصادر المعلومات

\begin{tabular}{|c|c|c|c|c|c|c|c|c|}
\hline \multirow{2}{*}{\multicolumn{2}{|c|}{ المجموع }} & \multicolumn{6}{|c|}{ مستوي وعى المبحوثات بمخاطر بعض الممارسات السلبية على صحة } & \multirow[t]{3}{*}{ المجلومات التعرض لمصادر } \\
\hline & & \multicolumn{2}{|c|}{ جيد } & \multicolumn{2}{|c|}{ متوسط } & \multicolumn{2}{|c|}{ ضعيف } & \\
\hline$\%$ & عدد & $\%$ & عدد & $\%$ & عدد & $\%$ & عدد & \\
\hline$r 9.0$ & 09 & 7 & IT & $V .0$ & 10 & 17 & rr & ضعيف \\
\hline OV.O & 110 & $r V$ & $V \varepsilon$ & 10 & $\Gamma$. & 0.0 & 11 & متوسط \\
\hline r & ז & 9 & 11 & r.o & v & .0 & 1 & جيد \\
\hline $1 \ldots$ & r.. & Or & $\begin{array}{ll}1.5 \\
07 .\end{array}$ & Tr & or & Tr & $\varepsilon \varepsilon$ & 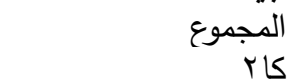 \\
\hline
\end{tabular}




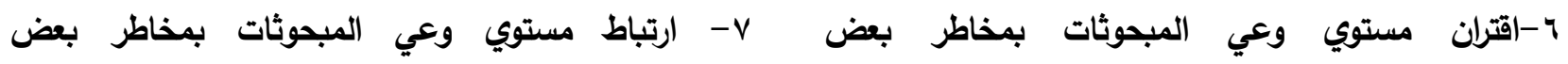

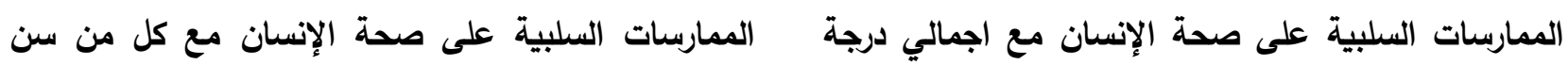
المبحوثة وسن الزوج وعدد سنوات الزواج: الاستفادة من مصادر المعلومات : تشير نتائج جدول (Y^) لوجود علاقة ارتباطية عكسية بين وعي المبحوثات بمخاطر بعض الممارسات السلبية على صحة الإنسان وكلا من المتغيرات المستقلة التالية سن بعن بعن المبحوثة وسن الزوج وعدد سنوات الزواج حيث بلغت قيمة

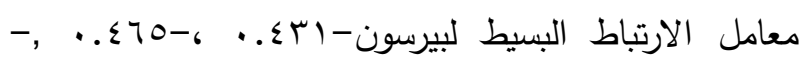

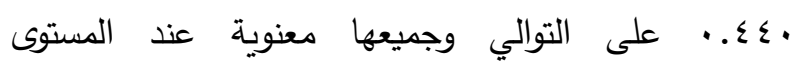
الاحتمالي ا .... مما يستلزم من المسئولين عند الحاجة لرفع مستوى الوعي بالمخاطر الصحية على الإنسان المصاحبة

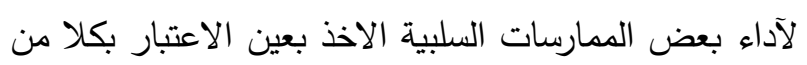
تشير نتائج جدول (rV) إلي وجود علاقة اقتران بين كلا من اجمالي درجة الاستفادة من مصادر المعلومات و ولتيز مستوي الوعي بالمخاطر الصحية لبعض الممارسات السلبية

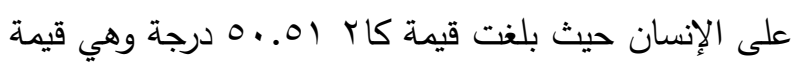

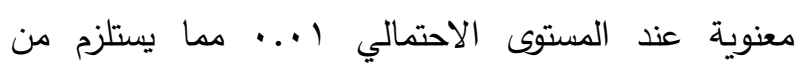
المسئولين عند الحاجة لرفع مستوى الوعي بالمخاطر الصحية على الإنسان المصاحبة لآداء بعض الممارسات السلبية الاهتمام بدرجة التعرض لمصادر المعلومات وذلك بتوجيه برامج ارشادية تتموية بمنطقة البحث. بله

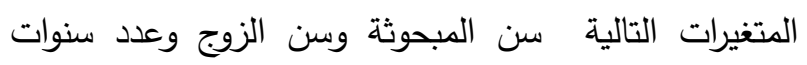

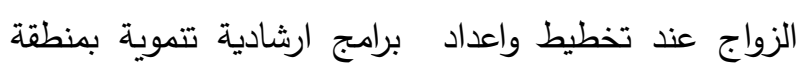

$$
\text { البحث. }
$$

جدول V.r. توزيع المبحوثات تبعا لمستوي وعيهن بمخاطر بعض الممارسات السلبية على صحة الإنسان و اجمالي درجة الاستفادة من مصادر المعلومات

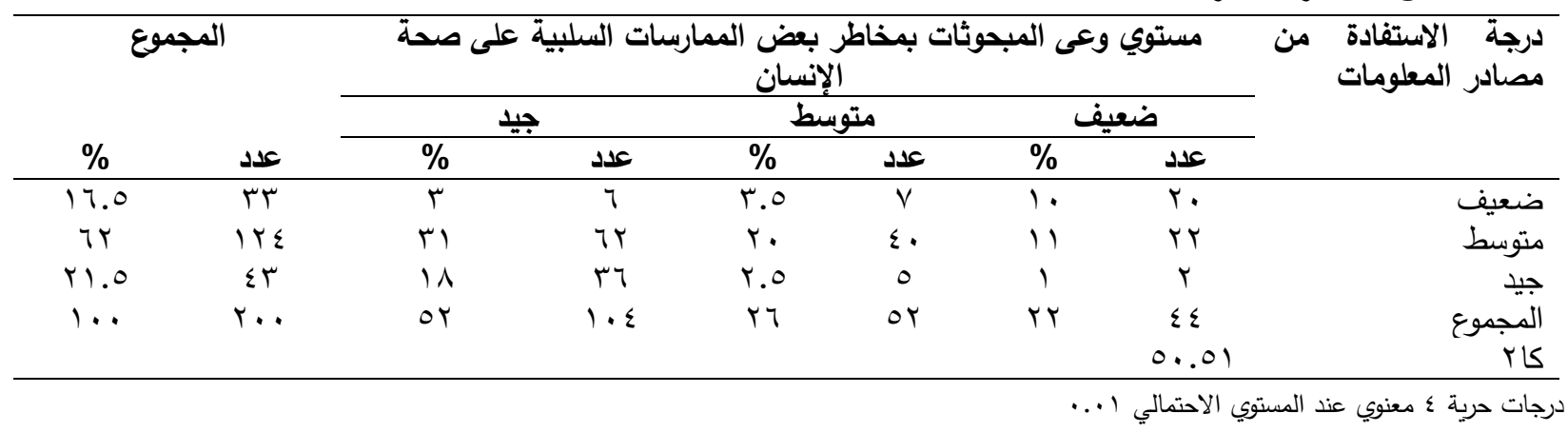

جدول ^ץ. قيم معامل الارتباط بين كل من سن المبحوثة ،و سن الزوج ،و عدد سنوات الزواج و مستوي وعي المبحوثات بمخاطر بعض الممارسات السلبية على صحة الإنسان

\begin{tabular}{|c|c|}
\hline المتغير التابع (وعى المبحوثات بمخاطر بعض الممارسات السلبية على صحة الإنسان) & المتغيرات المستقلة \\
\hline$* * \ldots \sum \Gamma-$ & سن المبحوثة \\
\hline$* * . .570-$ & سن الزوج \\
\hline *** . . $\leqslant \varepsilon .-$ & عدد سنوآت الزواج \\
\hline
\end{tabular}


بمحافظتي كفر الثيخ والغربية- رسالة دكتوراة - كلية

$$
\text { الزراعة- كفر الثيخ - جامعة طنطا. }
$$

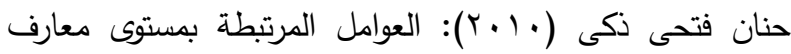
وممارسات الريفيات المتعلقة باستخدام المخلفات والمحافظة

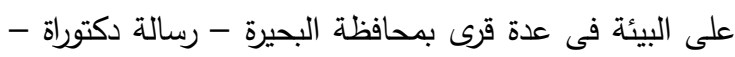
قسم الإقتصاد المنزلى - كلية الزراعة - جامعة الإسكندرية. رجاء على عبدالعاطى (Y V V) : تأثير برنامج إرشادى تعليمى على تتمية الوعى والسلوك البيئى لدى أطفال المرحلة الإبتدائية بمدينة الإسكندرية - رسالة دكتوراة - قسم الإقتصاد

$$
\text { المنزلى - كلية الزراعة - جامعة الإسكندرية. }
$$

سامر جميل رضوان (10 ب.r): السلوك الصحى والإتجاهات نحو

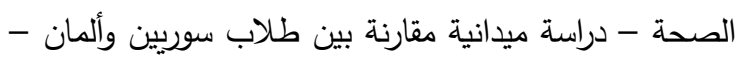

$$
\text { كلية التربية - جتمعة دمشق - سوريا. }
$$

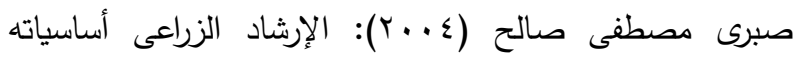

$$
\text { وتطبيقاته - مركز الإسكندرية للكتاب - الطبعة الأولى. }
$$

صلاح محمود النجار (ع . . ץ): إدارة المخلفات الصلبة - البدائل ، الإبتكارات ، الحلول - سلسلة أسس وآليات التتمية المستدامة - الجزء الثالث - الطبعة الأولى - دار الفكر الإبله

$$
\text { العربى - القاهرة }
$$

على حسين عبدالرازق و حسن محمود حسن (Y ( ا (Y): تمكين

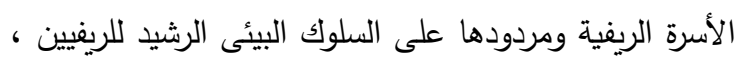

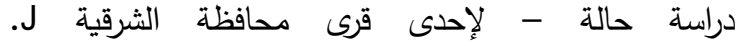
Agric.economic and Social . Mansoura Univ. يحيى على زهران ، زياد إبراهيم زيدان ، و أحمد مصطفى حمزة (Y.11)

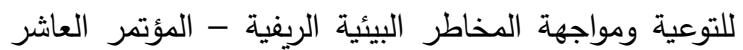

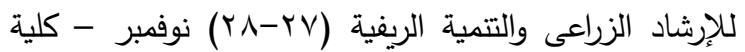
الزراعة - قسم الإرشاد والمجتمع الريفى - جامعة المنصورة.

\section{التوصيات}

1-الاهتمام بالبرامج التليفزيونية الصحية والبيئية الموجهة للمرأة الريفية في صور درامية بسيطة لنشر ورفع مستوى وعيها بالممارسات الصحية بين الريفيات. r-ادراج منطقة البحث ضمن مبادرة حياة كريمة. ب-زيادة الاهتمام بمحو أمية المرأة الريفية ورفع المستوى التعليمي لها حيث ارتبط المستوى التعليمي للمرأة الريفية طرديا مع اتباعها لبعض الممارسات اليومية الصحيحة. ع-تعزيز البرامج الارشادية الموجهة للمرأة الريفية بمنطقة البحث والتي تعمل على توعيتها بالمخاطر الصحية للممارسات السلبية التي تقوم بها. 0- الاخذ بعين الاعتبار سن المبحوثة وسن الزوج وعدد سنوات الزواج عند تخطيط واعداد وتتفيذ البرامج الارشادية التتموية بمنطقة البحث.

؟- العمل على تدريب القيادات النسائية وتتمية وعيهن البيئي والصحي عن طريق التأهيل والتدريب لنشر الوعي البيئي والصحي بين الريفيات.

\section{المراجع}

جابر أحمد بسيونى شحاتة ، وسوزان إبراهيم الثربتلى (ع . . ب): دراسة تأثير التلوث البيئى بين زراعة قرية سنهور فى مركز دمنهور بمحافظة البحيرة ، مجلة الجديد فى البحوث الزراعية - مجلد (9) العدد(1)- كلية الزراعة سابا باشا - جامعة الإسكندرية.

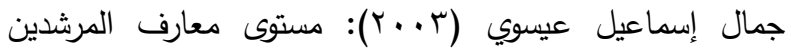
الزراعيين في مجال الاستفادة من بعض المخلفات النباتية 


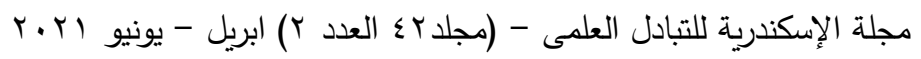

ABSTRACT

\title{
Rural Women's Awareness of The Dangers of some Negative Daily Practices on Human Health in one of The Villages of Kafr El Dawar Center, Beheira Governorate
}

\author{
Samira Ahmed Kandil , Enas Khamis , Hiam Hassib , Samia Abbas Mustafa
}

The research aimed mainly to identifying the level of awareness of rural women about the dangers of some negative daily practices on human health by achieving the following goals: Identifying some of the family and personal characteristics of the respondents, determining the general level of some negative daily practices of the respondents in the research area, determining the general level of the respondents 'awareness of some risks Negative daily practices on humans in the research area, studying the correlational relations between each of the respondents 'general awareness of the dangers of some negative daily practices on humans on the one hand and each of the independent variables studied on the other hand.

This research was conducted in Al-Wastaniya village, Kafr Al-Dawar Center, Al-Buhaira Governorate, where the size of the random sample of shells was 200 surveyed by $10 \%$ of the total. Tabular presentation, frequencies, percentages, arithmetic mean, standard deviation, Chi square and Pearson's simple correlation coefficient were used in the presentation and analysis of results.

The most important research results:

1 - More than a quarter of the sample is illiterate, and read and write, at a rate of $34.5 \%$.

2- More than half of the respondents have a good performance of negative practices related to methods and places of food preservation and storage, by $50.5 \%$.

3- The majority of respondents, $87.5 \%$, fall into the categories of weak and moderate awareness of health risks to humans associated with performing some negative practices related to some transactions inside the home.

4- The existence of an inverse correlation between the age of the respondent, the age of the husband, the number of years of marriage, and the level of general awareness of the health risks to humans associated with performing some negative practices related to some transactions inside the home. 